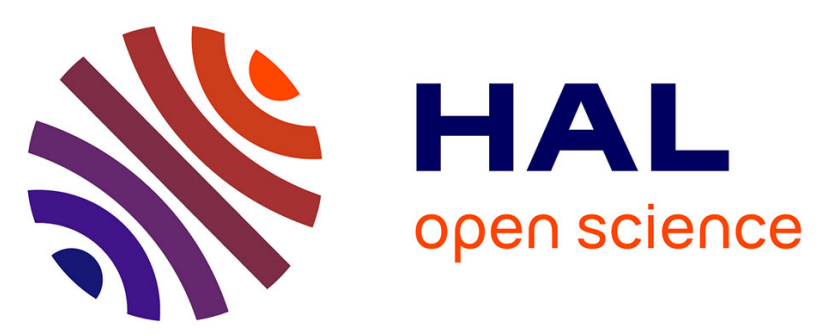

\title{
Acoustic turbulence measurements of near-bed suspended sediment dynamics in highly turbid waters of a macrotidal estuary
}

Aldo Sottolichio, David Hurther, Nicolas Gratiot, Patrice Bretel

\section{- To cite this version:}

Aldo Sottolichio, David Hurther, Nicolas Gratiot, Patrice Bretel. Acoustic turbulence measurements of near-bed suspended sediment dynamics in highly turbid waters of a macrotidal estuary. Continental Shelf Research, 2011, 31 (10), pp.S36-S49. 10.1016/j.csr.2011.03.016 . hal-00614447

\section{HAL Id: hal-00614447 https://hal.science/hal-00614447}

Submitted on 29 Sep 2021

HAL is a multi-disciplinary open access archive for the deposit and dissemination of scientific research documents, whether they are published or not. The documents may come from teaching and research institutions in France or abroad, or from public or private research centers.
L'archive ouverte pluridisciplinaire HAL, est destinée au dépôt et à la diffusion de documents scientifiques de niveau recherche, publiés ou non, émanant des établissements d'enseignement et de recherche français ou étrangers, des laboratoires publics ou privés. 
Provided for non-commercial research and education use. Not for reproduction, distribution or commercial use.

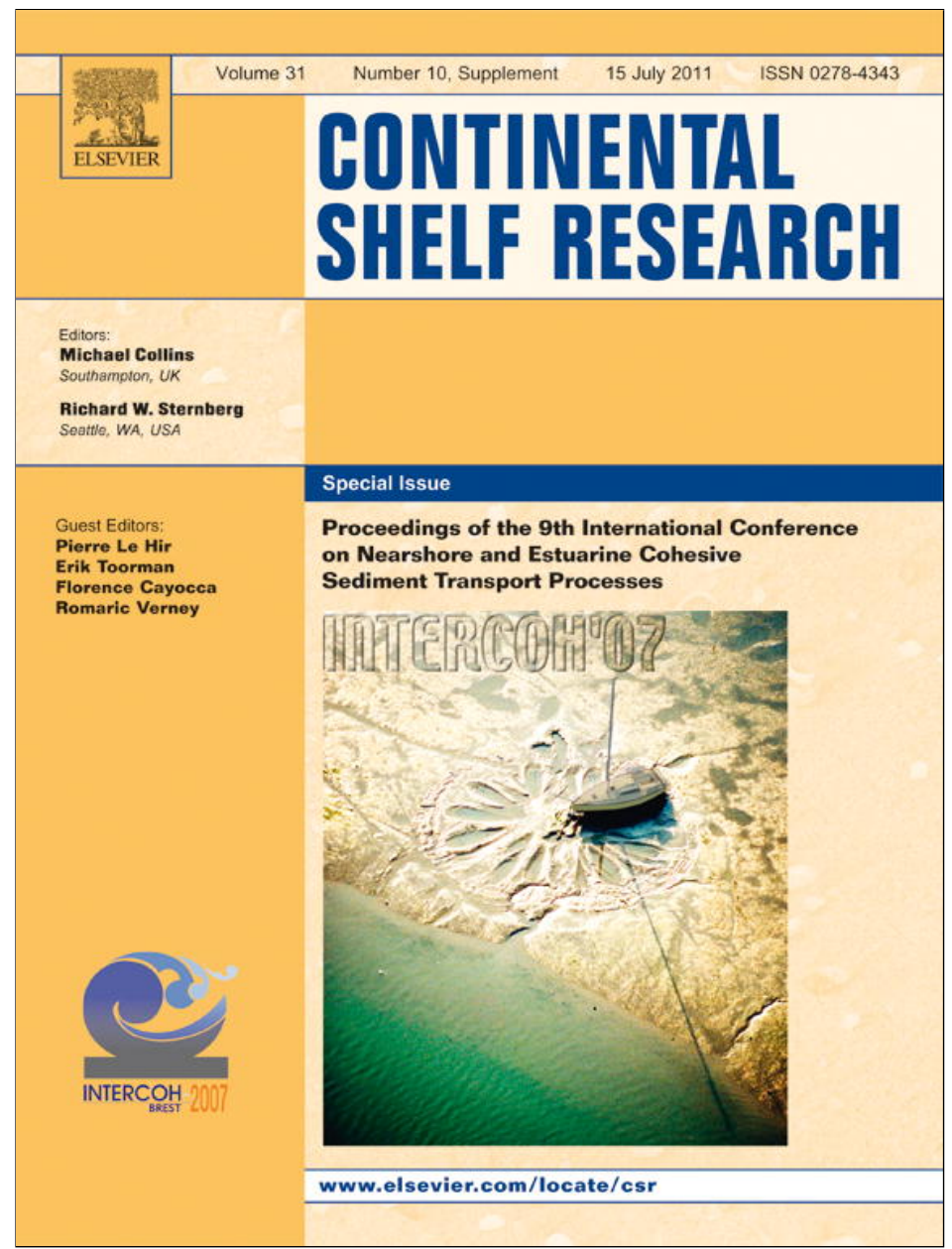

This article appeared in a journal published by Elsevier. The attached copy is furnished to the author for internal non-commercial research and education use, including for instruction at the authors institution and sharing with colleagues.

Other uses, including reproduction and distribution, or selling or licensing copies, or posting to personal, institutional or third party websites are prohibited.

In most cases authors are permitted to post their version of the article (e.g. in Word or Tex form) to their personal website or institutional repository. Authors requiring further information regarding Elsevier's archiving and manuscript policies are encouraged to visit:

http://www.elsevier.com/copyright 
Research papers

\title{
Acoustic turbulence measurements of near-bed suspended sediment dynamics in highly turbid waters of a macrotidal estuary
}

\author{
Aldo Sottolichio $^{\mathrm{a}, *}$, David Hurther ${ }^{\mathrm{b}}$, Nicolas Gratiot ${ }^{\mathrm{c}}$, Patrice Bretel ${ }^{\mathrm{a}, \mathrm{d}}$ \\ a University of Bordeaux I, UMR CNRS 5805 EPOC, Avenue des Facultés, 33405 Talence, France \\ b Laboratory of Geophysical and Industrial Fluid Flows (LEGI), CNRS-UJF-GINP, BP 53, 38041 Grenoble Cedex 9, France \\ ${ }^{c}$ Laboratoire de Transferts en Hydrologie et Environnement (LTHE), UMR CNRS 5564, IRD 1025, rue de la piscine, BP 53, 38041 Grenoble, France \\ ${ }^{\mathrm{d}}$ University of Caen, UMR CNRS 6143 M2C, 2-4 rue des Tilleuls, 14000 Caen, France
}

\section{A R T I C L E I N F O}

\section{Article history:}

Received 3 November 2008

Received in revised form

17 March 2011

Accepted 31 March 2011

Available online 19 April 2011

\section{Keywords:}

ADV

Suspended sediment concentration

Turbid water

Turbulent flux

Gironde estuary

Acoustic inversion

\begin{abstract}
A B S T R A C T
Sediment-turbulence interactions near the bed are still poorly understood in highly turbid estuaries, especially in the presence of fluid mud layers. This results primarily from the difficulty in measuring colocated velocity and suspended sediment concentration (SSC) at sufficiently high rate to resolve small turbulent flow scales. In this paper, we show how a set of commercial acoustic and optical backscattering systems known as ADCPs, ADVs and OBSs, can be deployed and used in a complementary way to perform large-scale profilings of tidal current and SSC combined with high-resolution velocity and SSC measurements in the highly turbid near-bed zone. The experiment was done in the Gironde estuary (France) which is well known for its turbidity maximum zone characterized by high SSC values, above $1 \mathrm{~g} \mathrm{l}^{-1}$ near the surface.

A first simple inversion method is proposed to convert the backscattered acoustic intensity measured with ADV into SSC data in the highly turbid near-bed zone. Near-bed SSC data from the OBS are used to compensate for the important acoustic sediment attenuation effect at an acoustic frequency of $6 \mathrm{MHz}$. No a priori knowledge of acoustic backscattering properties of mud suspensions is required with this calibration procedure. We obtain an attenuation coefficient for mud suspensions of $0.28 \mathrm{~m}^{2} / \mathrm{kg}$ at $6 \mathrm{MHz}$ leading to a good agreement between the SSC timeseries from the three ADV receivers and the OBS over the entire tidal cycle.

The obtained SSC data are then analyzed with respect to the near-bed velocity, Reynolds shear stress and turbulent kinetic energy (TKE) timeseries in order to identify the relevant sediment transport processes during the tidal cycle. Significant differences in bed shear stress and TKE levels are found between ebb and flood stages with effects on near-bed sediment dynamics. During the ebb, maximum levels of tidal current, bed shear stress and TKE are associated with a reduction of near-bed sediment concentration (from $400 \mathrm{~kg} \mathrm{~m}^{-3}$ down to $100 \mathrm{~kg} \mathrm{~m}^{-3}$ ). Bed liquefaction process is assumed to occur at this moment with the presence of highly concentrated mud layer and a possible lutocline at a distance of less than $20 \mathrm{~cm}$ above the bed. During the first $1.5 \mathrm{~h}$ of flood, turbulent activity remains moderate. The near-bed flood current is then inhibited very abruptly while a sudden increase in SSC occurred above the bed.

Assuming that the ADV is able to estimate relevant turbulent erosion fluxes, the co-located velocity and SSC are multiplied and compared with settling flux measurements made onboard under quiescent water conditions. The mean sediment settling fluxes (averaged over $3 \mathrm{~min}$ ) increase with SSC and are in relative good coherence with fluxes in quiescent water below the hindered regime, for SSC below $15 \mathrm{~g} \mathrm{l}^{-1}$. Reducing averaging time from $3 \mathrm{~min}$ to $30 \mathrm{~s}$ allows to increase the range of turbulent fluxes and SSC values, up to $99 \mathrm{~g} \mathrm{l}^{-1}$. At this scale, fluxes keep increasing quasi-linearly at higher SSC, suggesting the inhibition (delay or reduction) of the hindered settling regime as previously shown by Gratiot et al. (2005) from laboratory experiments. However, the 3-min averaged concentration field remained too low to conclude definitively on the effectiveness of such a process. Further analysis conducted at higher SSC regimes and under fully verified equilibrium are necessary.
\end{abstract}

(c) 2011 Elsevier Ltd. All rights reserved.

\section{Introduction}

Acoustic backscattering systems (ABS) have been developed and used intensively over the past twenty years in field and

\footnotetext{
* Corresponding author. Tel.: +335540008849; fax: +33556840848

E-mail address: a.sottolichio@epoc.u-bordeaux1.fr (A. Sottolichio).
}

laboratory studies of flow and sediment transport processes occurring in coastal, estuarine and inland flows (Thorne and Hanes, 2002). If velocity measurements can be considered as robust and reliable to date, the SSC measurements are still subject to open questions particularly when the suspended sediments differ in terms of size, shape and density from non-cohesive fine sand. Fine sand mixtures have been studied thoroughly in the 
literature providing the acoustic properties have been determined accurately (Thorne and Buckingham, 2004). The implementation of ABS such as ADCPs and ADVs in very turbid environments is not well documented. Some examples of relevant use of acoustic instruments are given by Fugate and Friedrichs (2002), Simpson et al. (2005) and Verney et al. (2007), working at suspended sediment concentrations (SSC) below $1 \mathrm{~g} \mathrm{l}^{-1}$. The main problems in turbid environments are related to unknown scattering and attenuation characteristics of the suspended sediments which are affected by flocculation processes (Gratiot et al., 2000). Whether flocculation affects or not the acoustic back- and total scattering cross section of very fine suspended sediments is still unknown at present. For this reason, the interpretation of near-bed, highly concentrated velocity and SSC measurements is usually subject to strong assumptions on the quality of the acquired data. Improvements in sediment concentration profiling based on ultrasonic inversions have recently been achieved when proper calibration can be performed. Examples are Merckelbach (2006), Tessier et al. (2008) and Thorne and Hurther (2009). For the ADVs, some recent work has been achieved to reveal relationships between acoustic backscattering strength (measured by acoustic Doppler velocimeters) and SSC in a wide concentration range, between 0.02 and more than $10 \mathrm{~g} \mathrm{l}^{-1}$ (Ha et al., 2009). This consisted of experiments in the laboratory, with calibrated suspended sediment. Even if acoustic inversion appears to be a powerful tool to investigate sediment dynamics, the performance in natural conditions for very fine suspended material at high concentrations (above $1 \mathrm{~g} \mathrm{l}^{-1}$ ) is still poorly assessed.

In very turbid macrotidal estuaries, fluid mud layers are common features. They can form on the bottom because of a high settling rate of suspended particles, which is generally associated with the maximum turbidity zone. Density stratifications induced by these highly concentrated suspensions can cause damping of turbulence generated in the bottom boundary layer (Le Hir et al., 2001; Winterwerp et al., 2001; Winterwerp, 2002). Thus, sediment-fluid interactions determine conditions of deposition or re-entrainment of sediment in the water column. In October 2004, a scientific survey was performed in the Gironde estuary with the objective of performing near-bed turbulence measurements with a consistent set of instruments. Turbulent fields of velocity and SSC were measured near bottom and throughout the water column during a complete tidal cycle with two optical backscatter sensors (OBS), two acoustic Doppler velocimeters (ADV), CTD with OBS sensor and an acoustic Doppler current profiler (ADCP).

In this paper, our purpose is to show how a set of complementary instruments can be deployed and used in highly turbid waters to identify the flow and sediment transport processes during an entire semi-diurnal neap tidal cycle, across the water column and within the near-bed zone. For this purpose, we will first present the inversion methods used to extract SSC from an ADV in the highly turbid near-bed region. The obtained results will be compared to SSC timeseries from calibrated OBS measurements to validate the methodology. Then, timeseries over the tidal cycle of tidal current profiles, near-bed velocities, turbulent Reynolds shear stress, TKE, SSC profiles and near-bed SSC, are analyzed and discussed in terms of sediment transport processes. Finally, in situ turbulent erosion fluxes are compared with settling flux under quiescent water conditions. It opens a discussion on the experimental work of Gratiot et al. (2005) concerning the possible effect of turbulence on hindered settling process.

\section{Field experiments and data processing}

\subsection{Background on the dynamics of the study site}

The Gironde estuary is a macrotidal estuary ( $6 \mathrm{~m}$ range at spring tide) situated in the SW of France. It is the largest estuary of Western Europe (Fig. 1a). The tide propagates $160 \mathrm{~km}$ upstream of the mouth located at the Atlantic Ocean. Mean river discharge is approximately $1000 \mathrm{~m}^{3} \mathrm{~s}^{-1}$, adding both freshwater inflows from the Garonne and the Dordogne rivers. The estuary is well known for its developed turbidity maximum, formed by the combined processes of tidal pumping and residual gravitational circulation. While tidal pumping is dominant under low river flow conditions, residual circulation acts especially during river flood events (Allen et al., 1980, Sottolichio et al., 2001). In the core of the turbidity maximum, typical SSCs are easily over $1 \mathrm{~g} \mathrm{l}^{-1}$ near the surface and several $\mathrm{g} \mathrm{l}^{-1}$ near the bottom. During neap tides, SSC tends to decay and high settling rates of suspended sediment lead to the formation of fluid mud layers on the bottom over a maximal thickness of about $2 \mathrm{~m}$ above the bed
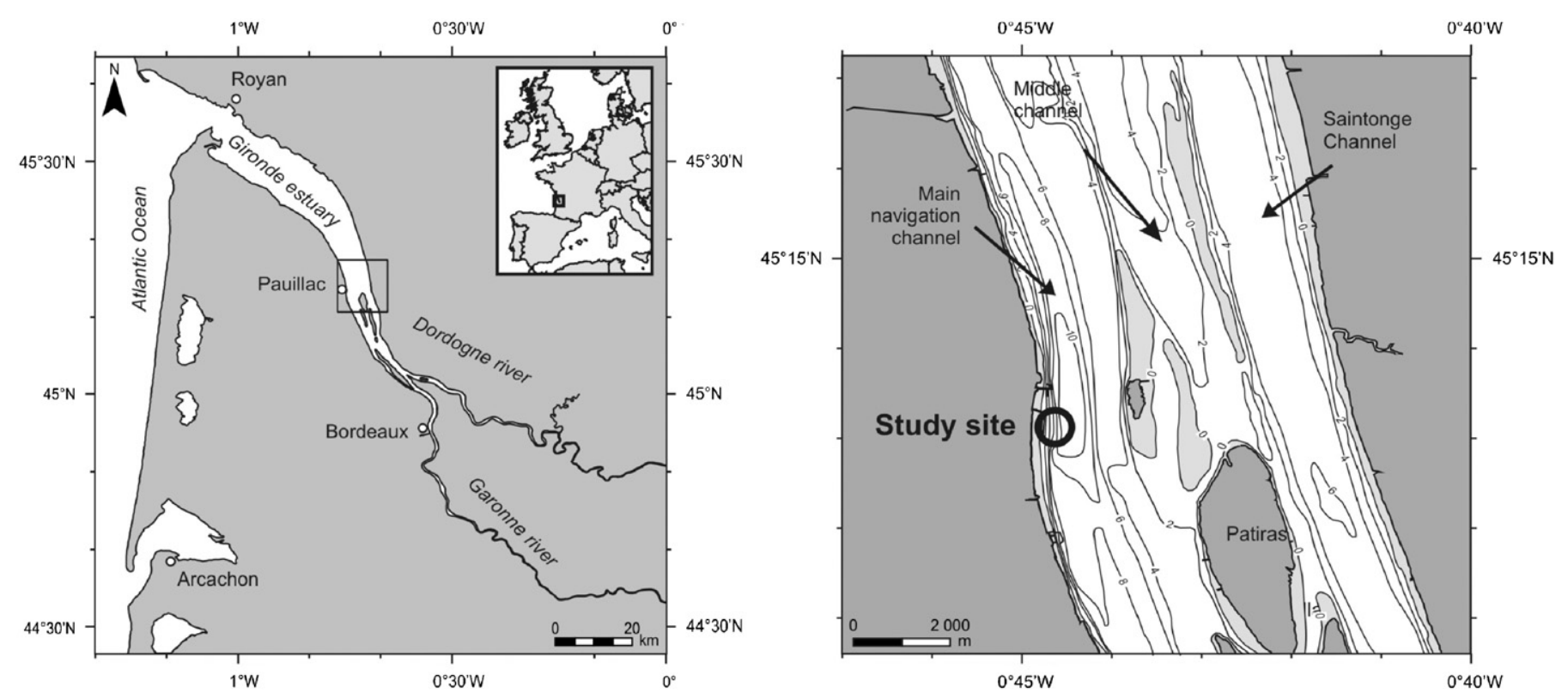

Fig. 1. Study site. Left: location of the Gironde estuary. Right: geomorphological description of the study site. 
and concentrations of several hundreds of $\mathrm{g}^{-1}$. A previous study combining in situ observations and numerical modeling (Le Hir et al., 2001) focused on fluid mud deposition and entrainment under tidal currents in the main channel. Two mechanisms appeared to be of great importance in bottom-water sediment exchanges and in the formation of fluid mud. The first is hindered settling in the concentration range of $20-200 \mathrm{~g} \mathrm{l}^{-1}$. The second is turbulence damping by turbidity-induced stratifications, which can explain lutocline events in this high-energy environment (current velocities are greater than $2 \mathrm{~m} \mathrm{~s}^{-1}$ during spring tides).

Echosounding detection of fluid mud layers in the navigation channel has been performed for years (Allen et al., 1977). Location of fluid mud depends directly on river discharge, which determines the location of the turbidity maximum along the axis of the estuary. However, the accurate prediction of the formation of fluid mud patches has become difficult because of the recent increase of dredging activities in the estuary. For the present study, we have chosen a straight zone of the navigation channel near Pauillac located $50 \mathrm{~km}$ upstream from the mouth (Fig. 1a). In this part of the estuary, turbidity in the water column is relatively high throughout the year (Sottolichio and Castaing, 1999). Furthermore, a smaller scale topographic depression nearby promotes conditions for a quasi-permanent presence of high near-bed SSC. Moreover, the bed is relatively flat at this site and covered with mud. For practical reasons and in order to avoid hazards of vessel traffic, the instruments were deployed at the edge of the channel, close to a pontoon (Fig. 1b). The depth was approximately $6 \mathrm{~m}$ at low water.

\subsection{Instrumentation deployment and data acquisition}

An experimental benthic frame was developed, combining two Acoustic Doppler Velocimeters (ADV Vector, Nortek) and two optical turbidity sensors (OBS from D\&A Inst.) fixed at different levels above the sediment bed. The ADVs (working at the acoustic frequency of $6 \mathrm{MHz}$ ) continuously recorded the $u, v$ and $w$ velocity components at a sampling frequency of $32 \mathrm{~Hz}$. One of them (Vector 1) was located $22 \mathrm{~cm}$ above the bed and was horizontally oriented. The other one (Vector 2) was positioned $85 \mathrm{~cm}$ above the bed, oriented upwards (Fig. 2). As the measuring point is at a distance of $15 \mathrm{~cm}$ from the acoustic emitter, Vector 2 measures at $1 \mathrm{~m}$ above the bed. Two OBS turbidimeters provided SSC data. The lowest OBS was placed $4 \mathrm{~cm}$ above the bed. The highest OBS was the closest to Vector $1,10 \mathrm{~cm}$ above. Later in the text, the lowest OBS will be referred to as "near-bed OBS" and the highest OBS as "upper OBS".

A survey of the water column dynamic was performed by an ADCP Workhorse from RDI, operating at a frequency of $600 \mathrm{kHz}$. The bottom-tracking profiler was mounted in a floating buoy attached $20 \mathrm{~m}$ from the hull of the vessel. The vessel was double anchored at its front and rear in order to limit its movements due to swinging. Therefore, the ADCP could be considered to be measuring at a fixed point. The ADCP scanned the water column from $40 \mathrm{~cm}$ below the surface down to the bed. Surface wave amplitude, even under strong wind conditions, were small enough to ensure a steady vertical position to the ADCP, with limited pitch and roll. The instrument continuously recorded instantaneous velocities at $1 \mathrm{~Hz}$ a

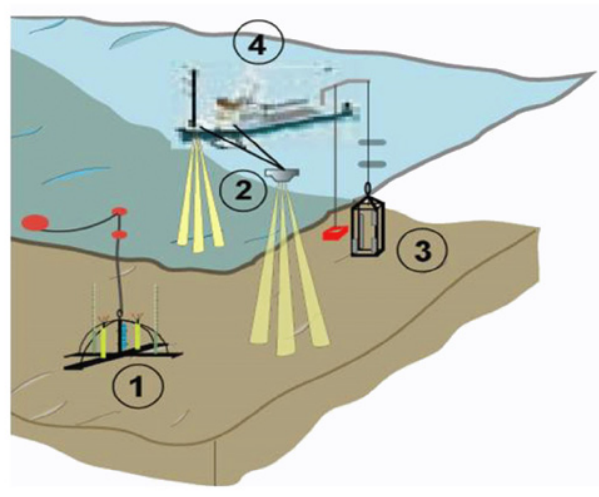

b

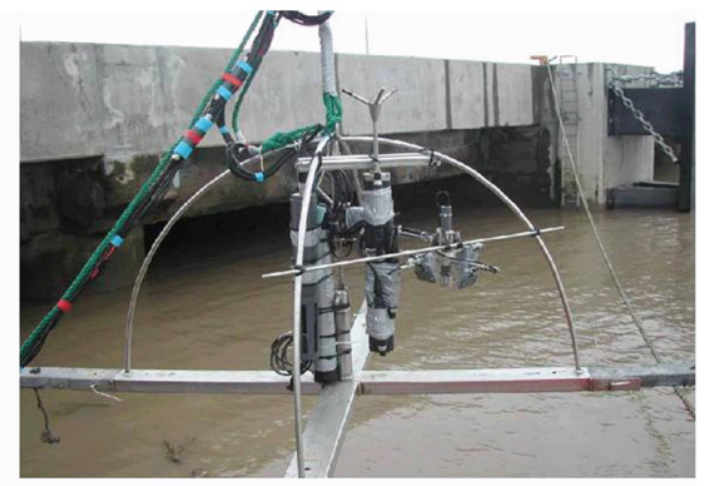

C

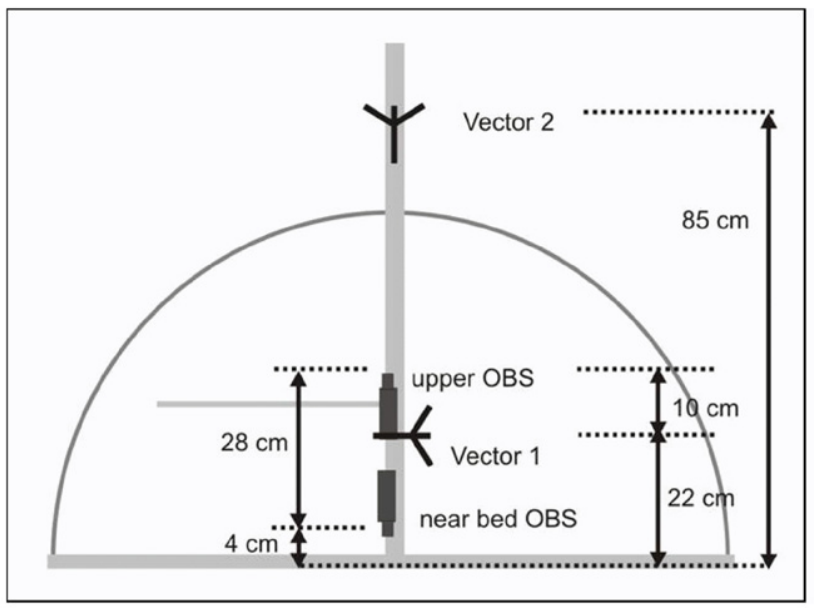

Fig. 2. (a) Sketch showing the field deployment: (1) benthic structure, (2) bottom tracking ADCP, (3) CTD probe and (4) sedimentation onboard. (b) Picture of the benthic frame deployed. (c) Sketch of the frame with the position of near-bed instrumentation (ADVs and OBSs). 
frequency, considering cells of $1 \mathrm{~m}$ vertical height. Current values were averaged over $10 \mathrm{~min}$. Finally, vertical CTD and concentration profiles were performed every $45 \mathrm{~min}$ with an OBS-3A probe (D\&A Inst).

At different times, samples of turbid water and fluid mud were taken with a Niskin bottle to determine sediment settling flux $\Phi$ under quiescent conditions. Settling experiments were carried out onboard immediately after sampling in a cubic tank. The time dependent vertical profiles of suspended sediment concentration $C(z, t)$ have been measured using a Bergen Nautik multi sensor system (Gratiot, 2004). The instrument operates with backscatter infrared sensors (emission at $950 \mathrm{~nm}$ during $10 \mathrm{~ms}$ ) that are embedded in a plastic bar. The sensors are spaced at $9 \mathrm{~mm}$ intervals. There are 32 sensors in total, which give a measuring profile of approximately $28 \mathrm{~cm}$ high.

Following the work of You (2004), the settling velocity $w_{s}(h, t)$ at a depth $h<H$ below water surface is deduced from the equation of mass conservation:

$w_{s}(h, t)=\frac{\int_{0}^{h}[C(z, t)-C(z, t+\Delta t)] d z}{\int_{t}^{t+\Delta t} C(h, t) d t}$

where $C$ is the concentration, $w_{s}$ settling velocity, $z$ the vertical coordinate, $h$ the total height (here $h=28 \mathrm{~cm}$ ) and $t$ the time. The origin of coordinates is located at the free surface with the $z$-axis downwards. Here we assumed that the settling is a 1DV process and thus we neglect recirculation within the tank. Twelve trials were undertaken for mixtures of mean concentration varying in the range $0.5-80 \mathrm{~g}^{-1}$. Results are presented in 'Discussion section'.

The two OBSs used near the bottom, as well as the OBS-3A profiler probe, were calibrated in the laboratory with natural Gironde mud in order to provide mass concentration in the range $0-300 \mathrm{~g} \mathrm{l}^{-1}$. Fig. 3 shows the SSC versus OBS output used for the calibration of two of the sensors. All the sensors have very similar behavior, as first reported by Kineke and Sternberg (1992): OBS output voltage increases for moderately increasing SSC (backscattering light range), and decreases exponentially for high SSC (absorption range). In this case, OBS output voltage increases up to $9.6 \mathrm{~V}$ for a SSC value of $18 \mathrm{~g} \mathrm{l}^{-1}$. Between 18 and 25-30 $\mathrm{gl}^{-1}$, the OBS output remains constant at $9.6 \mathrm{~V}$. This corresponds to a saturation range for the sensor, before a decrease for SSC higher than $30 \mathrm{~g} \mathrm{l}^{-1}$. With the exception of the [18-30] $\mathrm{g} \mathrm{l}^{-1}$ plateau, OBSs provide SSC estimates up to about $300 \mathrm{~g} \mathrm{l}^{-1}$.

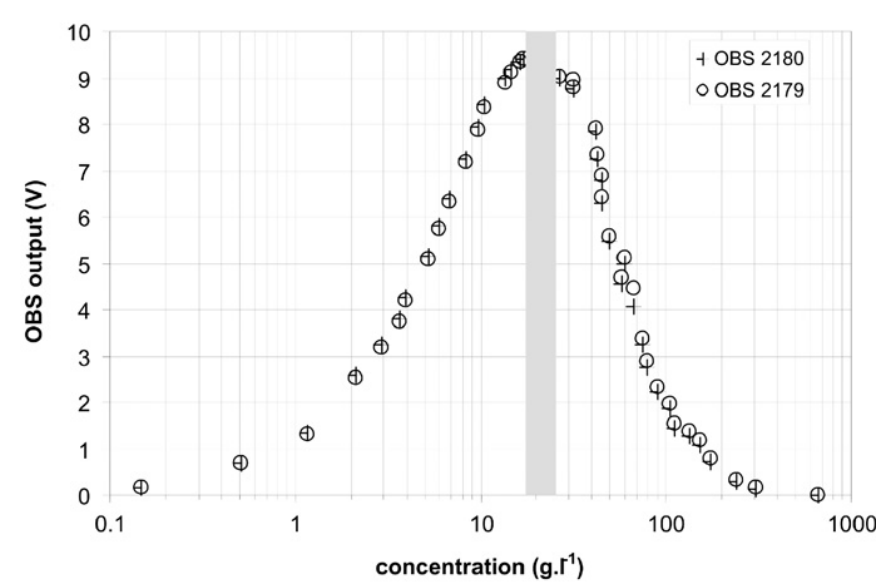

Fig. 3. Laboratory calibration of two OBS sensors, in the concentration range of the Gironde estuary. The gray bar shows the "saturation range" of the OBSs, between 18 and $28 \mathrm{~g} \mathrm{l}^{-1}$ approximately.

\subsection{Acoustic nearbed measurements of SSC using an ADV}

In order to analyze the flow and sediment transport processes during a tidal cycle, we propose to estimate the SSC from the near-bed ADV data collected with Vector 1 . The high-resolution signal at $32 \mathrm{~Hz}$ provided by the ADV is meant to provide near-bed SSC timeseries at turbulent scales. We start from the expression of the backscattered acoustic intensity I valid under the assumptions of negligible multiple scattering and incoherent scattering, as given in Thorne and Hanes (2002)

$\langle I\rangle=P_{H} P_{B} \frac{C}{r^{2}} \exp (-4 \alpha r)=K C \exp \left(-4 \alpha_{s} r\right)$

where $C$ is the suspended sediment mass concentration (the variable to determine) at a fixed distance $r=15 \mathrm{~cm}$ from the transducer.

$P_{H}$ is called the hardware parameter since it depends on the hardware and sensor characteristics such as electronic sensitivity and transfer function, transducer radius, power of the transmitted acoustic pulse.

$P_{B}$ is the backscattering parameter which describes the backscattering properties of the suspended sediments.

$\alpha=\alpha_{w}+\alpha_{s}$ corresponds to the attenuation coefficient resulting from the cumulative contributions of the attenuations due to water absorption and the presence of suspended sediment along the travel path of the acoustic pulse. As seen in Eq. (2), these terms constitute the attenuation term since they contribute to a damping of the received acoustic intensity with distance from the transducer.

The terms $P_{H}, P_{B}$ and $\alpha_{w}$ are unknown constants in our experimental conditions which can be regrouped with the constant denominator $r^{2}$, into a single inversion constant $K$. This constant will be determined by the in situ calibration described below.

Eq. (2) has been derived by Thorne and Hanes (2002) for backscattering conditions in a monostatic configuration, i.e. when a single acoustic transducer is used as an emitter and receiver. The ADV Vector configuration corresponds to a multi-bistatic configuration (the emitter is separated by the receiver) composed of three identical bistatic geometries. The validity of Eq. (2) for the present ADV configuration and scattering conditions needs to be verified carefully. This step is crucial in order to avoid any systematic application of the ABS model given by Eq. (2) to an ADV system which could lead to significant errors in the SSC calculations.

\subsubsection{Validity of backscattering approximation}

As shown in Thorne and Hanes (2002), the backscattering parameter is defined as

$P_{B}=\frac{\left\langle a_{s}^{2} f_{B}^{2}\right\rangle}{\rho_{s}\left\langle a_{s}^{3}\right\rangle}$

where $a_{s}$ is the value of a given radius class constituting the granulometric sediment size distribution, $\rho_{s}$ is the density of the suspended sediments. $f_{B}$ is known as the form function and describes the backscattering properties of the sediments. Please note that the brackets notation in Eq. (3) means that the expression in between is size distribution weighted such as $\left\langle a_{s}^{2} f_{B}^{2}\right\rangle=$ $\int a_{s}^{2} n\left(a_{s}\right) f_{B}^{2}\left(a_{s}\right) d a_{s}$ with $n\left(a_{s}\right)$ being the probability number size distribution of the sediment in suspension.

At first instance Eq. (3) is only valid for a monostatic configuration (transmission and reception of the acoustic signals are done with the same transducer) since $f_{B}$ corresponds to a backscattering form function at an angle of $180^{\circ}$. This is not the case for the bistatic configuration of the ADV Vector used here since the three receiver sensors are separated from the emitter sensor. Recently, Moore and Hay (2009) have demonstrated that for turbulent suspensions constituted of small solid particles, the departure of angular scattering strength from the backscattering 
strength is negligibly low as long as $k\left\langle a_{s}\right\rangle<1$ (Rayleigh scattering regime) and the scattering angle is larger than $130^{\circ}$. In our suspension conditions, the mean sediment radius is found to be less than $25 \mu \mathrm{m}$ from the in situ calibration and the acoustic frequency is equal to $6 \mathrm{MHz}$ which results into $k\langle a\rangle \cong 0.6$. The scattering angle of the bistatic configuration is equal to $150^{\circ}$ (calculated from Nortek user manual specifications). Consequently the deviation of angular scattering from backscattering strength can be considered as negligibly low and the backscattering relation in Eq. (3) can be applied here for the bistatic configuration of the Vectors.

\subsubsection{Geometrical simplification based on Vector bistatic configuration}

The attenuation terms in Eq. (2) could be simplified to exp[ $-4 \alpha r]$ from the relation $\exp \left[-2 \alpha\left(r_{1}+r_{2}\right)\right]$ because the distances from the transmitter to the sampling-volume $\left(r_{1}\right)$ and from the samplingvolume to the receiver $\left(r_{2}\right)$ are identical, such as $r=r_{1}=r_{2}$. It must be remembered here that this simplification does not apply to all bistatic configurations.

\subsubsection{Simplification of sediment attenuation term}

The sediment attenuation term in Eq. (2) is defined as

$\exp \left(-4 \alpha_{s} r\right)=\exp \left(-4 \int_{0}^{r} \zeta_{s} C d r\right)$

where $\zeta$ is directly proportional the total scattering cross section of the sediment. When this term cannot be neglected, Eq. (2) becomes implicit in $C$ and its inversion can be subject to important instabilities (Thorne and Hanes 2002). In the present conditions, this attenuation term cannot be neglected due to the high SSC values encountered in the benthic region of the Gironde estuary. However, we assume negligible concentration gradients over the distance separating the emitter from the receivers. This allows the following simplification:

$\exp \left(-4 \int_{0}^{r} \zeta_{s} C d r\right)=\exp \left(-4 \zeta_{S} C r\right)$

In order to verify the previous simplification of the sediment attenuation term, the acoustic intensity signals $\langle I\rangle_{A D V, i}$ for each receivers $i$ of Vector 1 have been compared in Fig. 4 . As can be seen, the sensors have very similar values $\left(r^{2}\right.$ between 0.94 and 0.99 ), although the travel paths of the sound pulses are oriented along very different directions for the three bistatic axes. The best correlation is seen between receivers 1 and 3, while a few data between receivers 2 and 3 show less good correlation. Please note that receiver 2 is positioned slightly higher than receivers 1 and 3 (located at the same level because Vector 1 is in a horizontal position). Whether this can be explained by spatial inhomogeneities in the concentration field between the vertical and the horizontal directions could not be verified herein. However, only very few events in the tidal cycle are concerned.

\subsubsection{ADV intensity relation}

The previous considerations lead to the following intensity/ SSC relation valid for each receiver $i$ of Vector 1 :

$C_{i, A D V}=\frac{\langle I\rangle_{A D V, i}}{K_{i}} \exp \left(4 \zeta_{S} C_{i, A D V} r\right)$

where $\langle I\rangle_{A D V, i}$ is the output signal, proportional to the acoustic intensity. In our experiment, the inversion is performed for Vector 1 only, as there were no OBS deployed near Vector 2 for an on-site calibration procedure.
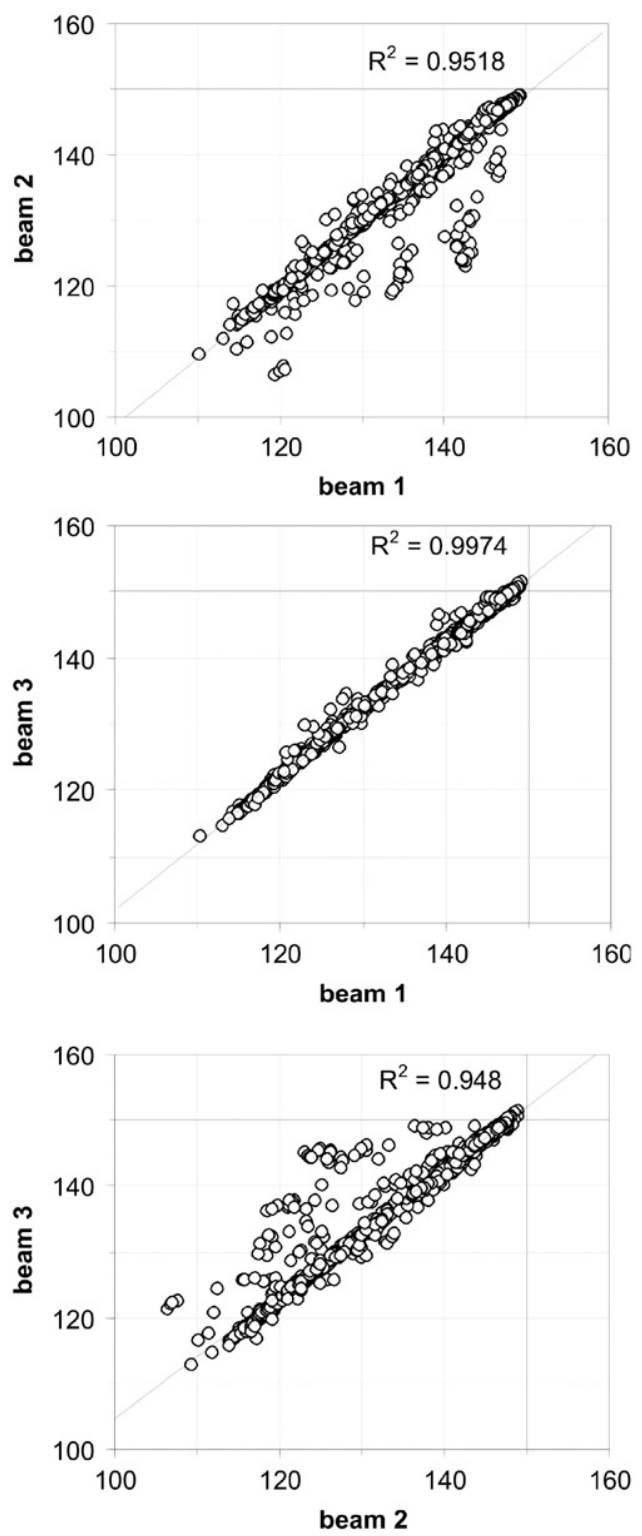

Fig. 4. Correlation between amplitude values recorded by each of the three beams of Vector 1 during the field experiment. Values recorded at $32 \mathrm{~Hz}$ were averaged over $1 \mathrm{~s}$.

\subsubsection{Determination of inversion constants}

The inversion of Eq. (6) requires that the coefficients $K_{i}$ and $\zeta_{s}$ have been determined previously. Generic formulations of the backscattering properties are available in the literature for suspended marine sand mixtures (Thorne and Buckingham, 2004; Thorne and Meral, 2008). The very fine suspended sediments in the Gironde estuary are subject to flocculation process for which the scattering characteristics might differ from non-cohesive fine sand. In order to perform on-site calibration an OBS has been positioned at the closest distance of $10 \mathrm{~cm}$ from the ADV Vector 1. This is achieved in two steps. First, $K_{i}$ is obtained by a best linear regression between $\langle I\rangle_{A D V, i}$ and $C_{O B S}$ in the low concentration range $\left(C<0.8 \mathrm{~g} \mathrm{l}^{-1}\right)$. Both quantities are time averaged over a duration of $180 \mathrm{~s}$ in order to eliminate the turbulent fluctuations in both signals. In the second step, a best linear fit for all the data is performed, between $\left(\langle I\rangle_{A D V, i} / K_{i}\right) \exp \left(4 \zeta_{S} r C_{O B S}\right)$ and $C_{O B S}$ using $\zeta_{s}$ as the free parameter. In Fig. 5, straight crosses represent $\langle I\rangle_{A D V, i} / K_{i}$ versus $C_{O B S}$. It can be seen that sediment attenuation effects appear above $2 \mathrm{~g} \mathrm{l}^{-1}$. This value is close to the one obtained by $\mathrm{Ha}$ et al. (2009) in laboratory experiments with mud mixtures using different commercial ADVs. The crosses in Fig. 5 are the ADV 


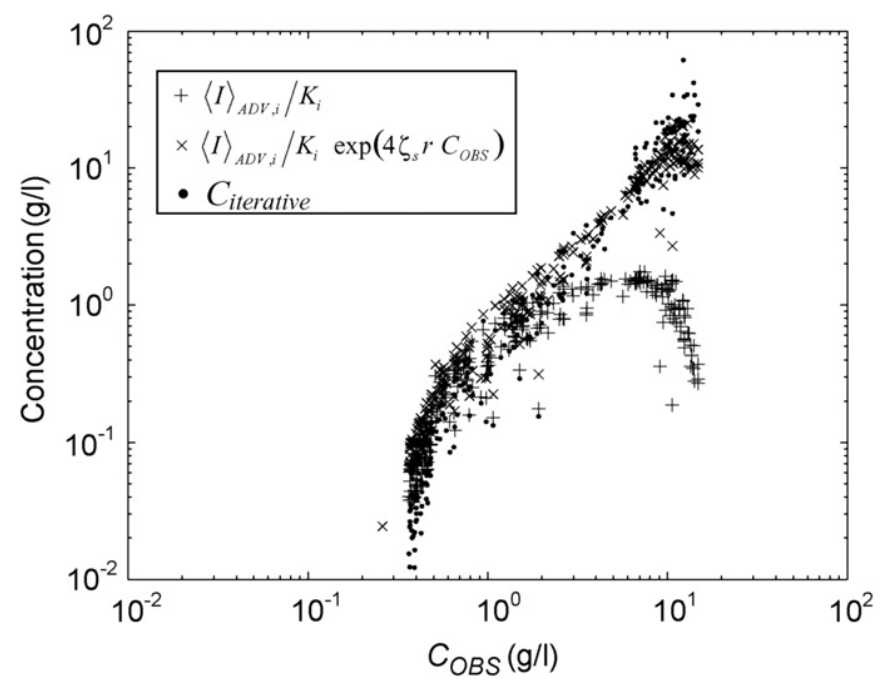

Fig. 5. SSC inverted from ADV ("Concentration") versus SSC from OBS (" $C_{\mathrm{OBS}}$ ") in the range $0-15 \mathrm{gl}^{-1}$. Right crosses: raw $\mathrm{ADV}$ data not compensated, crosses: compensated data $(\zeta=0.28)$, black dots: concentration from the iterative method.

data compensated for attenuation effects $\left(\langle I\rangle_{A D V, i} / K_{i}\right) \exp \left(4 \zeta_{S} r C_{O B S}\right)$. As it can be observed, the curve remains linear over a much larger sediment concentration range. The best linear fit was obtained for an attenuation coefficient value of $0.28 \mathrm{~m}^{2} / \mathrm{kg}$ at an acoustic frequency of $6 \mathrm{MHz}$. Finally, the concentrations from ADV and computed with the iterative method are also plotted (Fig. 5, dotted curve). They allow to confirm the calibration procedure.

Because the acoustic characteristics of mud suspensions are unknown at present, the obtained attenuation factor value could not directly be compared to other literature results. If the generic formulations valid for non-cohesive fine sand are applied here to determine the equivalent mean sediment diameter (see Thorne and Hanes, 2002), a value of $45 \mu \mathrm{m}$ is obtained with $\zeta_{s}=0.28 \mathrm{~m}^{2} / \mathrm{kg}$ at $6 \mathrm{MHz}$. A second solution is found in the $\mathrm{mm}$ range but it is considered as physically meaningless.

Problems in the calibration procedure can be seen in Fig. 5 for concentration below $0.4 \mathrm{~g} \mathrm{l}^{-1}$. In this range, the slope of the calibration curve is different from the one obtained for $C>0.4 \mathrm{~g} \mathrm{l}^{-1}$. This might be induced by the non negligible distance of $10 \mathrm{~cm}$ separating the OBS measurement volume from the ADV sample volume. However, because the dynamic concentration range observed during the tidal cycle lies between 0.5 and $20 \mathrm{~g} \mathrm{l}^{-1}$ (see Fig. 7), no specific correction of these low concentration data has been applied.

\subsubsection{Inversion method}

A full inversion of Eq. (6) using the calibrated parameters $K_{i}$ and $\zeta_{s}$ has been applied to all data assuming its validity for turbulent fluctuations and considering that a correlation coefficient of $r^{2}=0.79$ is satisfactory for these unusual experimental conditions. The well known implicit iterative inversion method (Thorne et al., 1993; Thorne and Hardcastle, 1997; Thorne and Hanes, 2002) is implemented to extract $C_{i, A D V}$ from the implicit Eq. (6). The result over the tidal cycle is shown in Fig. 7 for the mean concentration averaged over a time period of 3 min.

\section{Results and discussion}

3.1. Overview of tidal flow and suspended sediment conditions in the water column

In this section we present general hydrological conditions prevailing at the mooring point during the experiment. In the Gironde estuary at the little town of Pauillac, the tidal cycle is semi-diurnal and asymmetric, with flood shorter than ebb. Prevailing hydrodynamic conditions during the experiment were characterized by weak river flow (less than $300 \mathrm{~m}^{3} \mathrm{~s}^{-1}$ ) and neap tide (tidal range of $2.30 \mathrm{~m}$ ). Under these conditions, tidal currents are particularly weak and sediment resuspension is expected to be low. Fig. 6a shows the current velocity recorded by the ADCP during three consecutive tidal cycles (values averaged over $10 \mathrm{~min}$ ), starting on October 5, 2004 at 15:00 (set to hour 0). Current patterns show ebb dominance, with $90-100 \mathrm{~cm} \mathrm{~s}^{-1}$ for the maximum ebb velocity near the surface, and only $45 \mathrm{~cm} \mathrm{~s}^{-1}$ for the maximum flood velocity. These values are weak, considering typical maximum currents of $2.5 \mathrm{~m} \mathrm{~s}^{-1}$ that can be measured in the channel under spring tide conditions (Le Hir et al., 2001).

The ADCP recorded currents for $45 \mathrm{~h}$, but here we focus on one tidal cycle, beginning at hour 7 (22:00 local time). Despite neap tide conditions and the very small tidal range during the $13 \mathrm{~h}$ experiment, the water column is well mixed, which is favored by the low river input. Salinity (in PSU) is homogenous over the water column (Fig. 6c) and varies from 5 at low tide to 11 at high tide. During the beginning of the ebb tide (around hour 9), a slight vertical salinity gradient can be observed in the lower water column, which disappears at hour 11 when ebb accelerates. Another weak and short salinity gradient appears during the flood stage (hour 17), because salinity intrusion starts near the bottom. It has to be noted that there is an abnormal decay of salinity during flood (hour 18). This is probably due to a local input of freshwater downstream from the anchor station. Indeed, there are several little channels or streams along the Gironde estuary. These natural channels drain freshwater and some of them drain rainwater and urban sewage water after treatment. At the anchor station, this causes at the end of low water slack a decrease of salinity at the surface. When vertical mixing grows during accelerating flood, the decay of salinity spreads throughout the entire water column. Afterwards, the advection of salt water leads to a general increase of salinity. Below the depth of $-5 \mathrm{~m}$, salinity values show some inverse gradients near bottom. This may be an effect of differential advection, as the bottom layer is affected by bottom friction and higher viscosity due to fluid mud. As a result, bottom water could remain fresher despite advection of downstream salt water in the layer above. However, this must be consider as an hypothesis, as we cannot rule out that the inverse gradients can also result from an instrument artifact, since very high mud concentration can cause an underestimate of conductivity measured by the CTD probe (Maillet, pers. comm.).

Suspended sediment concentrations obtained from CTD + OBS3A vertical profiles are shown in Fig. 6b. Pulses of sediment concentration up to 3-4 $\mathrm{gl}^{-1}$ are observed in the water column between hours 7 and 9 , between hours 10 and 11 and between hours 18 and 20 . The rest of the time, SSCs are lower than $1 \mathrm{~g} \mathrm{l}^{-1}$, with typical values of $0.5 \mathrm{~g} \mathrm{l}^{-1}$, which are representative of neap tide conditions. Two concentration peaks can be associated with bottom resuspension: the first small peak occurs at hour 10:30 (during ebb), the second, more intense, at hour 18 , at early flood. High concentration at hours 7 and 8 may be due to previous flood resuspension rather than advection from downstream. Low river flow conditions prevailing during the experiment allow the upstream shift of the salinity intrusion and the associated turbidity maximum, far upstream from the location of the experiment point. This is probably why the recorded values are in general lower than typical concentrations of the core of the turbidity maximum. Moreover, neap tides promote deposition, leading to weak resuspension and rapid sediment depletion of the water column. Consequently, a strong vertical gradient of concentration occurred near the bottom with the formation of a fluid mud layer, at least $30-40 \mathrm{~cm}$ thick. This layer exhibits a wavy pattern probably due to a disruption effect of the 

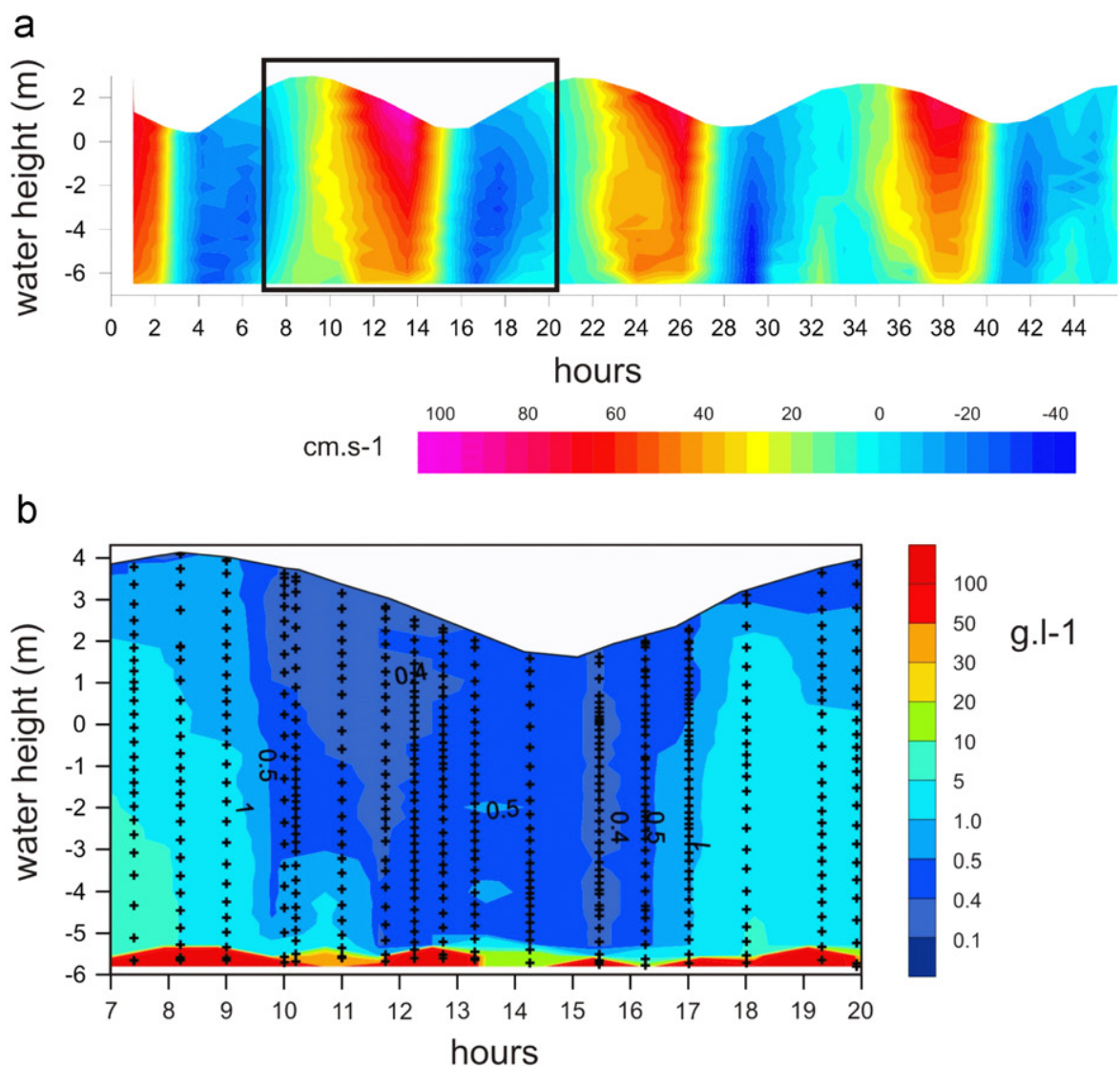

C

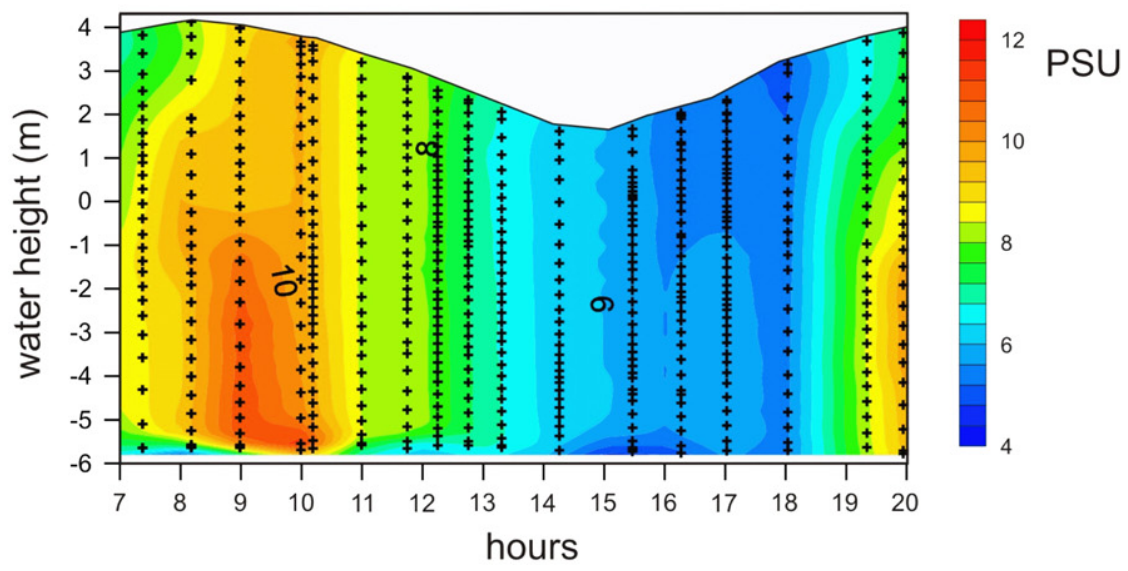

Fig. 6. Hydrographic measurements in the water column over the field experiment. (a) Horizontal current velocities measured from the ADCP (North component). Considering estuary orientation, ebb currents are positive. (b) Vertical distribution of suspended sediment concentration measured with the OBS-3A probe calibrated in the laboratory. (c) Vertical distribution of salinity measured with the CTD-OBS-3A probe. Abnormal decrease during flood (hour 18) is due to a local input of freshwater. Black crosses indicate location of raw data. The vertical scale in the water is relative to the local lowest water level at spring tide. By this way we avoid to set 0 at the free surface or at the bed, as both are expected to vary on time (by the tide propagation or by sediment erosion/deposition, respectively).

probe when reaching the bed. However, the layer does not mix in the water column during the tidal cycle considered.

\subsection{Performance of the acoustic devices for SSC measurements}

In this section, we present results of the inverted acoustic intensities as described in Section 2.2. Fig. 7 shows the results of the acoustic inversion for near-bed data obtained with the ADV. In Fig. 7a, time evolution of near-bed currents and water depth are illustrated for a better understanding of SSC records presented below. Fig. $7 \mathrm{~b}$ shows the raw data of the acoustic amplitude recorded by Vector 1 at $32 \mathrm{~Hz}$. For more clarity, only record from Beam 1 is presented. There is clear high-frequency variability of amplitude, superimposed to rapid fluctuations due to changes in SSC in the field.

The ADV inversion for Vector 1 used the SSC values from the "upper OBS" placed at $10 \mathrm{~cm}$ above (Fig. 7c). The distance of $10 \mathrm{~cm}$ can be too large in the case that the devices are in a very stratified fluid mud layer. However, during the experiment there is no lutocline between the upper OBS and Vector 1, and therefore concentrations are equivalent most of the time, excepted for slack water periods, when vertical gradients can form during particle settling. As shown in Fig. 5, the application of the attenuation compensation enhances the dynamics of the ADV record. This can also be seen when comparing the range of values given by raw 
a
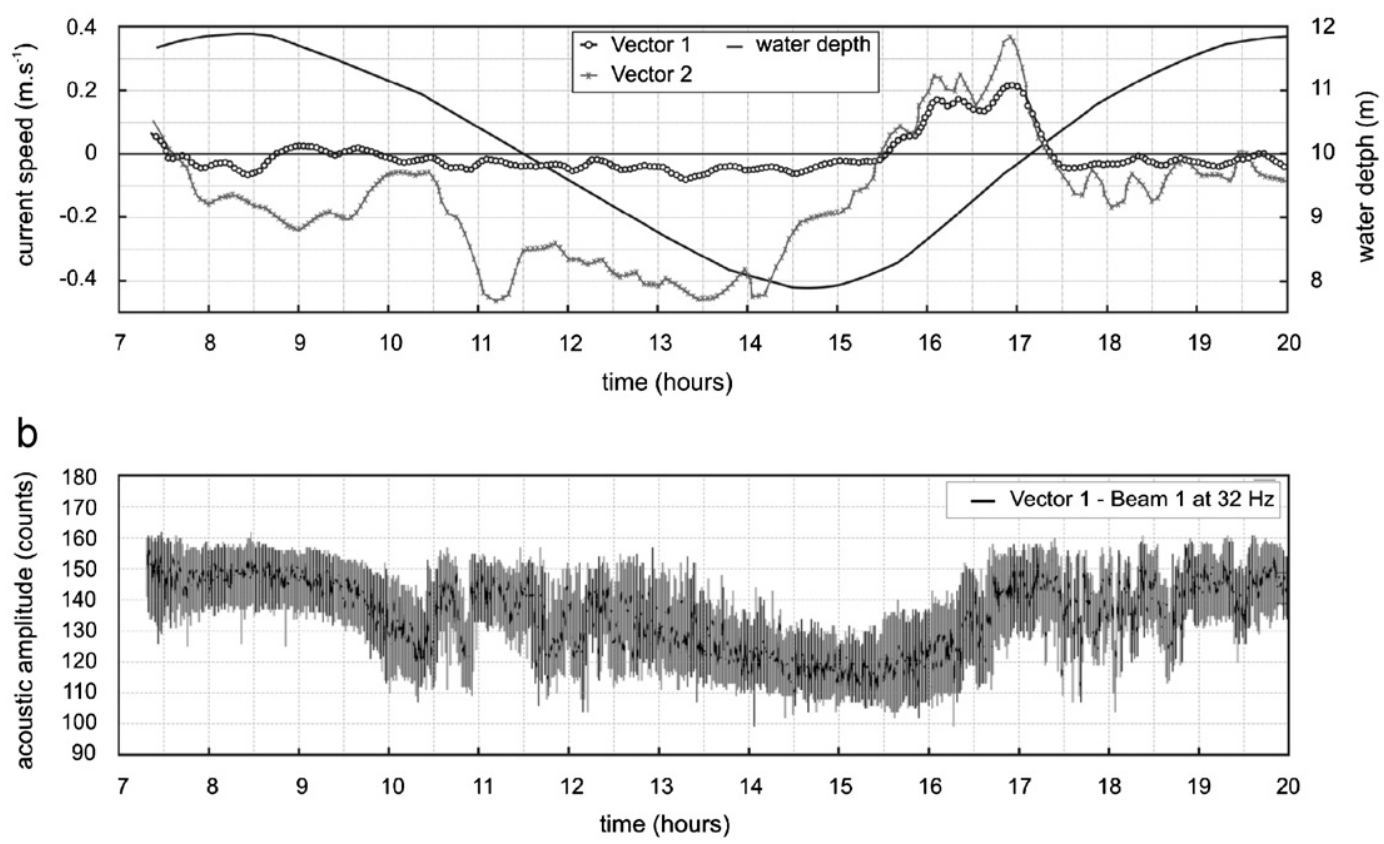

C

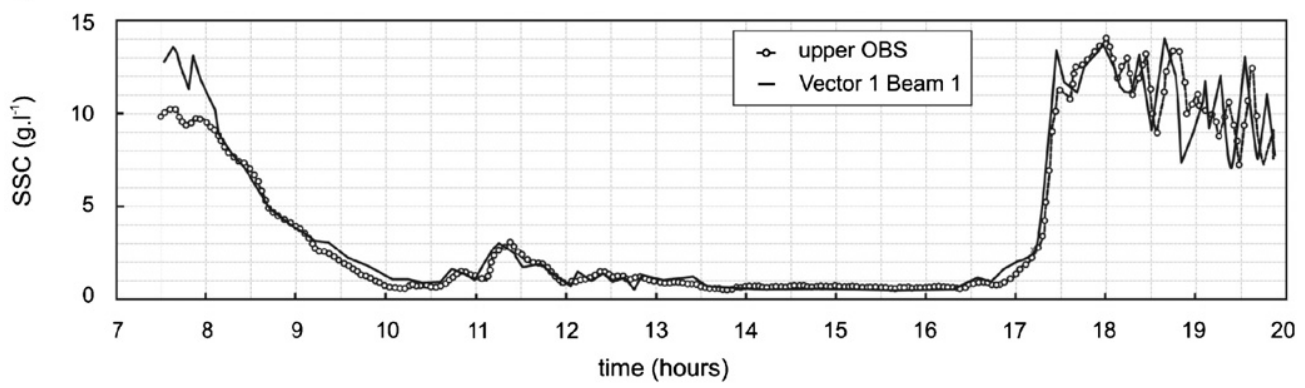

Fig. 7. Near bed measurements over a tidal cycle. (a) Near-bed current velocity from Vectors 1 and 2 and water depth. Flood currents are positive; (b) $32 \mathrm{~Hz}$ raw data of acoustic amplitude measured by beam 1 of Vector 1; (d) SSC from upper OBS and from inversion of beam 1 of Vector 1 . Values are averaged over 3 min.

data (acoustic amplitude, Fig. 7b) and calculated SSCs (Fig. 7c). The latter highlight contrast in concentration between ebb and flood phases. In general, SSC levels are very similar to the values of the OBS in the range $0-15 \mathrm{~g} \mathrm{l}^{-1}$ (Fig. 7c). Except for the starting period of the record (from 7.30 to 8.30 ), the SSC data fit well together supporting the validity of the proposed ADV inversion method. The $10 \mathrm{~cm}$ difference in height between the two devices could probably explain the bad fit during the first hour of the record (between hours 7 and 8). High water slack promotes particle settling and a relatively significant vertical concentration gradient could form. Consequently the OBS, which is the upper device, records lower values than the ADV.

\subsection{Near-bed dynamics derived from acoustic and optical records}

Detailed near-bed measurements during the semi-diurnal tidal cycle are illustrated in Figs. 7 (already commented) and 8. Fig. 8a (as Fig. 7a) shows the record of the horizontal velocity measurements from the two ADVs and the total water depth measured by the pressure sensor of Vector 1. Near-bed current velocity recorded from the ADCP is also shown in Fig. 8a. Values from Vectors 1 and 2 are averaged over $3 \mathrm{~min}$, while ADCP data are taken every $10 \mathrm{~min}$. It should be remembered that the benthic frame was positioned at a horizontal distance of 20-30 m from the ADCP. Moreover, the "ADCP at bed" is the velocity recorded by the cell closest to the bed and uncontaminated by bed echoes, typically located $1 \mathrm{~m}$ above the bed and integrated over $1 \mathrm{~m}$ height. Despite the differences in measurement locations and resolutions, there is a good correspondence between the timeseries of the ADCP and the two Vectors. The record starts $1 \mathrm{~h}$ before high water and continues for $13 \mathrm{~h}$. The acceleration during ebb until hour 14 , the consecutive deceleration and the reversal to flood is recorded simultaneously by the three devices. The damping occurring at the beginning of ebb (from hours 10 to 11) is recorded by Vector 2 and by the ADCP showing the consistency of this flow feature over scales of several tens of meters. Moreover, the overall coherence of the independent acoustic velocity records tends to validate the quality and the relevance of the data.

Current speeds exhibit a stronger vertical gradient during ebb than during flood phase. During ebb phase, Vector 2 ( $1 \mathrm{~m}$ above the bottom) shows in general more current variability than Vector 1 ( $22 \mathrm{~cm}$ above the bottom). Maximum velocity is reached between hours 13 and 14 (around $0.45 \mathrm{~m} \mathrm{~s}^{-1}$ ). During the flood (starting at 15:30), there is a similar response at both Vectors, with clear acceleration between hours 16 and 17 and a maximum velocity at hour 17 (around $0.25 \mathrm{~cm} \mathrm{~s}^{-1}$ for Vector 2 and $0.20 \mathrm{~cm} \mathrm{~s}^{-1}$ for Vector 1 ). The asymmetry between ebb and flood and the stronger vertical gradient during ebb are also observed in the timeseries of turbulent shear $u^{\prime} w^{\prime}$ (Fig. 8b), which is significantly higher at Vector 1 at maximum ebb $\left(0.014 \mathrm{~m}^{2} / \mathrm{s}^{2}\right)$. Flood phase is characterized by a lower shear which is consistent with a weaker vertical gradient of horizontal velocity during this phase. 
a

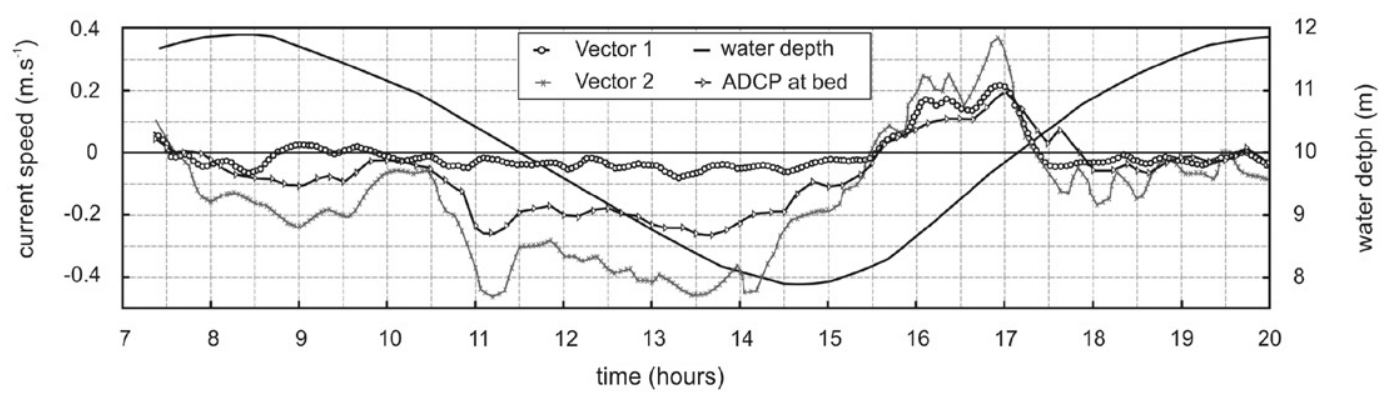

b

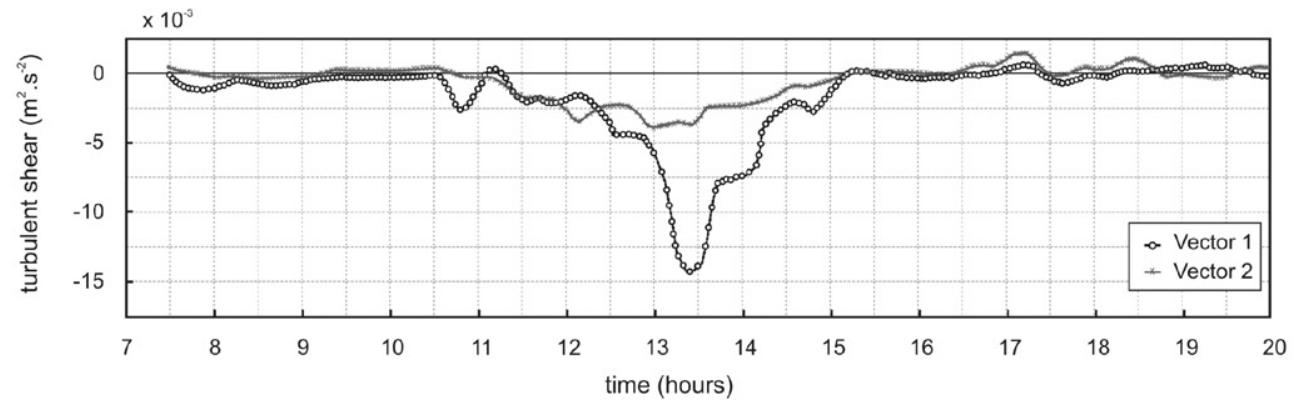

C

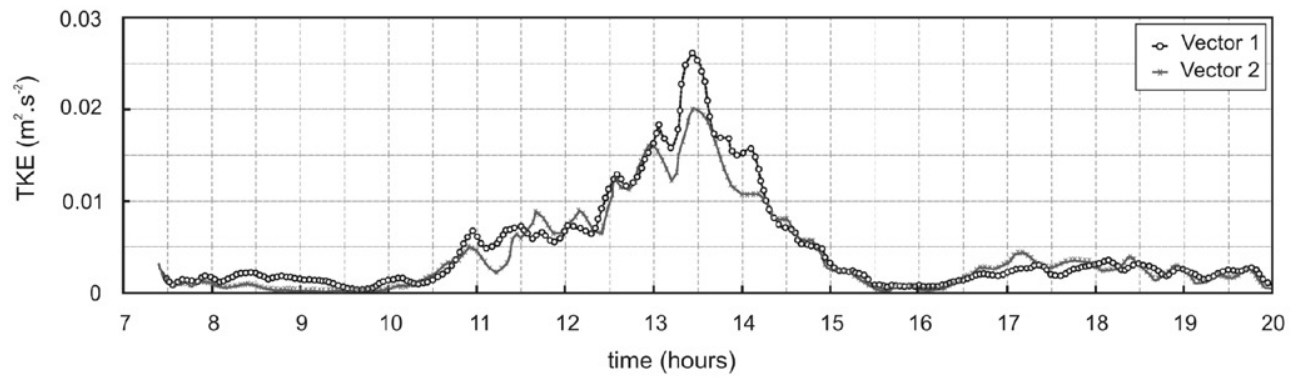

d

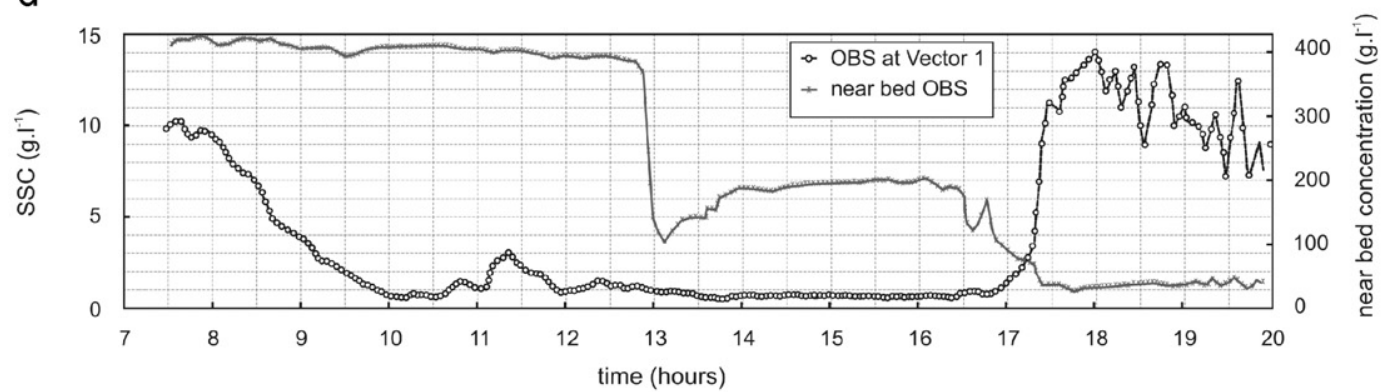

Fig. 8. Near bed measurements over a tidal cycle. (a) Current velocity from Vector 1 and Vector 2, water depth (same as in Fig. 7) and bottom current velocity from the ADCP. Flood currents are positive; (b) turbulent shear $u^{\prime} w^{\prime}$, (c) TKE, (d) suspended sediment concentration from upper OBS at Vector 1 (scale on the left axis) and from near-bed OBS (scale on the right axis).

Peak values of shear during final ebb are particularly high (14 Pa), as no equivalent values have been reported in the literature. During this event, the correlation rate of raw velocities recorded by the ADV decreased below $70 \%$, which is a threshold value of good quality of the data (Lane et al., 1998). The low correlations suggest the presence of high turbulent flows (Martin et al., 2002) and possibly overestimations due to noise in the turbulence record (Cea et al., 2007). When large velocity gradients appear within the sample volume, the noise due to shear becomes important (Martin et al., 2002). However, in our record less than $5 \%$ of the samples were under the value of $70 \%$ correlation. In addition, following Voulgaris and Trowbridge (1998), noise values associated with velocity shear are not significant and can be ignored. Therefore, the high shear values calculated here cannot be due to bad quality data. However, the location of the anchor station, very close to the floating pontoon, suggests that the flow in this portion of the channel could be disturbed by an artificial effect. Shear during ebb could be due to large velocity fluctuations in the wake of some obstacle, explaining such a large shear stress.

Another interesting parameter is the turbulent kinetic energy, expressed as

$$
T K E=\frac{1}{2} \sqrt{\bar{u}^{\prime 2}+\bar{v}^{\prime 2}+\bar{W}^{\prime 2}}
$$

Values of TKE are shown in Fig. 8c. Averaging velocities every $3 \mathrm{~min}$ reveals fluctuations in horizontal velocities at a 
characteristic period of $15-20 \mathrm{~min}$ (Fig. 8a). These oscillations are clearly visible in the evolution of the mean TKE (Fig. 8b). It is likely that these low frequency fluctuations are due to the local effect of topography on the flow, or even to the proximity of the pontoon. However, they will not be discussed here. When looking at short-term variations during the tidal cycle, TKE shows a strong asymmetry between the ebb and flood phases. During ebb phase, TKE starts to increase after high water slack (before hour 12), with similar responses at the two Vectors. At hour 13, Vector 1 shows an increase with respect to Vector 2. Maximum values occur just after hour $13.5\left(0.028 \mathrm{~m}^{2} \mathrm{~s}^{-2}\right)$ and are followed by a steady decrease until the end of the ebb. During the flood stage, TKE starts to increase between hours 16 and 18 , but remains extremely weak during the whole phase. As discussed above for turbulent shear values, these TKE values are particularly high over a muddy bed. At this stage of analysis, it is satisfactory that good coherence exists between the set of parameters, such as (i) vertical gradients of mean velocity between Vectors 1 and 2, showing higher gradients during ebb; (ii) asymmetry of turbulent variables between ebb and flood, with more intensity during ebb; and (iii) coherence of TKE values between Vectors 1 and 2, both showing the same trends.

The physical processes that govern the sediment dynamics show significant differences between the ebb and flood stages and are consistent with patterns observed in the water column by the OBS-3A probe. Fig. 8d shows SSCs measured by the upper OBS and by the "near-bed OBS". As recorded by the upper OBS, from hours 7 to 10 , SSC decreases to less than $1 \mathrm{~g} \mathrm{l}^{-1}$ along high water slack. Ebb resuspension starts at hour 11, causing a weak SSC increase $\left(\sim 3 \mathrm{gl}^{-1}\right)$. This is followed by a decrease until hour 14 , when SSCs reach minimum values (less than $1 \mathrm{gl}^{-1}$ ). Concentration remained low until the beginning of the flood. At hour 17, a second increase occurs, correlated with maximum flood. Between hours 17 and 18, there is a rapid increase in SSC, up to $15 \mathrm{~g} \mathrm{l}^{-1}$, which corresponds to a decrease in velocity (Fig. 8a). Concentrations remain high until the end of the observed tidal cycle. Nearbed concentration (given by near-bed OBS) spread in the range of fluid mud (i.e. several hundreds $\mathrm{g}^{-1}$ ), and values change strongly during the tidal cycle. The record starts before high water with a poorly consolidated, highly concentrated bed. At this time, concentration is out of the calibration range of the OBS $\left(0-300 \mathrm{gl}^{-1}\right)$ and is estimated to be above $400 \mathrm{~g} \mathrm{l}^{-1}$ by extrapolating the calibration curve (see Fig. 3). At hour 13, there is an abrupt decrease of concentration, from more than 300 to $120 \mathrm{~g} \mathrm{l}^{-1}$ in less than $20 \mathrm{~min}$. The reason of this change is unclear, and two hypothesis can be advanced. The first is due to the liquefaction of the bed and a dilution by injection of water in a highly sheared environment (entrainment processes). The second is the advection of the fluid mud patch. Indeed, concentration decrease occurs when the turbulent shear is close to its maximum value at Vector 1 (Fig. 8b). The fact that SSC at Vector 1 does not increase simultaneously is inconsistent with the liquefaction of the bed, and more consistent with the hypothesis of lateral advection of fluid mud. Considering differences in concentration between the two OBSs, a plausible hypothesis could be that a lutocline was generated somewhere between 4 and $32 \mathrm{~cm}$ above the bed. During the decelerating ebb, from hour 13 to hour 16:30, bed concentration increases again, but slowly, up to $200 \mathrm{~g} \mathrm{l}^{-1}$, suggesting deposition or lateral advection of fluid mud. The consecutive flood resuspension (hour 17:30) causes another decrease of near-bed concentration. Resuspension during flood is stronger than the one that occurred during the ebb, and concentration decreases to a minimum value of $35 \mathrm{gl}^{-1}$. It is reasonable to deduce that the lutocline is partly destructured by this event.

\subsection{Turbulent flux measurements in concentrated benthic suspensions}

One of the most challenging aspects of sediment transport studies consists in calculating in situ instantaneous turbulent sediment fluxes $\left(u^{\prime} c^{\prime}, v^{\prime} c^{\prime}, w^{\prime} c^{\prime}\right)$. This appears to be crucial for applied modeling purposes but also for a better understanding of processes acting in concentrated benthic suspension (CBS) layers, characterized by concentrations of few grams per litre or more. In high energy tidal estuarine environments, estimation of turbulent sediment flux $\left(w^{\prime} c^{\prime}\right)$ is complicated by cohesive properties of fine sediment. Measurements within fluid mud are also rare and difficult to obtain in such environments because of the episodic conditions of formation and persistence of highly concentrated layers.

\subsubsection{Previous laboratory experiments on CBS}

At a microscale, interaction between turbulence and concentrated benthic suspension produces flocculation/breakage processes with some feedback effects that are not yet fully understood (Manning and Bass, 2006). From laboratory experiments, Gratiot and Manning (2004) and Gratiot et al. (2005) demonstrated that shear stresses existing near bed in high energy concentrated environments produce a high variety of flocs with different sizes and settling velocities (over several decades). The volumic concentration of flocs leads to hindered settling under quiescent conditions when sediment concentration exceeds a few grams per litre. This well-known mechanism has been characterized from both experimental and analytical approaches (Toorman, 1992, among others).

Under turbulent conditions, the processes are expected to be radically different, as pointed out by the experimental laboratory work of Gratiot et al. (2005). Experiments were realized in a plexiglas tank, containing $40 \mathrm{~cm}$ of fluid mud mixtures. The vertical stirring of a grid, located near the bottom of a tank, generated a controlled diffusive turbulent flux which counterbalanced the sediment settling flux. When sediment concentration exceeded one gram per liter, a lutocline appeared, settled and stabilized at a depth $z_{\ell \infty}$, after tens of minutes to a few hours. The turbulent settling flux $\phi$ at the equilibrium was then calculated from $z_{\ell \infty}$ and constants depending on the geometry of the grid and sediment characteristics

$\phi=\left(\frac{0.6 z_{0}}{z_{\ell \infty}}\right)^{4} \frac{k_{0}^{3 / 2}}{G z_{0}}$

where $G, k_{0}$ and $z_{0}$ are the constants. The reader can refer to Gratiot et al. (2005) for further technical details.

As shown in Fig. 9a, hindered effects under turbulent conditions revealed to be reduced to such a degree that sediment flux increased for sediment concentration up to $100 \mathrm{~g} \mathrm{l}^{-1}$.

While experiments were conducted under purely diffusive turbulent, it was interesting investigating whether the results of Gratiot et al. (2005) would remain true for naturally sheared flows.

\subsubsection{Mean turbulent fluxes versus settling fluxes within CBS in natural conditions}

In the present study, settling fluxes $w_{s} c$ under quiescent conditions were obtained from onboard sedimentation experiments (Fig. 9b, crosses and solid line). Values showed an increase from $1.10^{-4}$ to $7.10^{-3} \mathrm{~kg} \mathrm{~m}^{-2} \mathrm{~s}^{-1}$ for SSC values up to $13 \mathrm{~g} \mathrm{l}^{-1}$. Hindered settling started for concentrations greater than $13 \mathrm{gl}^{-1}$ so that settling flux started decreasing continuously for higher concentration. A value of $2.10^{-3} \mathrm{~kg} \mathrm{~m}^{-2} \mathrm{~s}^{-1}$ was obtained for the maximum concentration tested (about $70 \mathrm{gl}^{-1}$ ). At this concentration, the water-sediment mixture is widely in the range of fluid mud.

Mean turbulent erosion fluxes $\overline{w^{\prime} c^{\prime}}$ determined from the ADV measurements are also plotted in Fig. 9b. Fluxes were obtained 
a

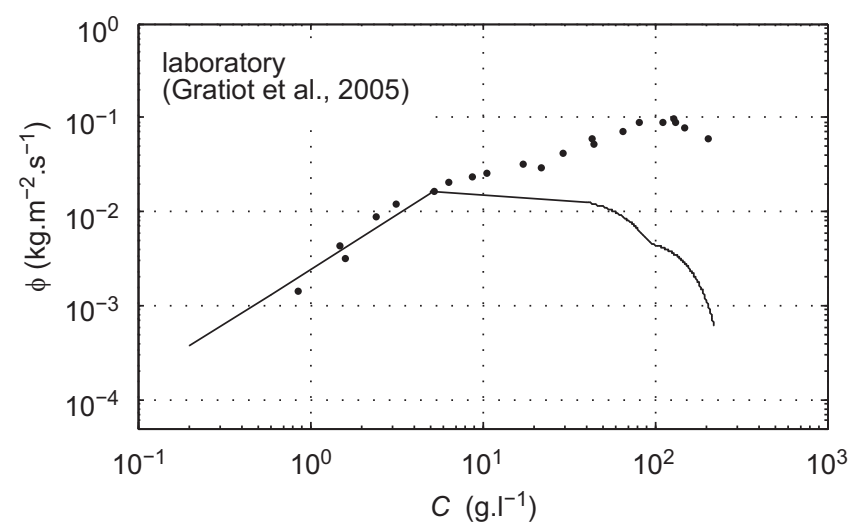

b

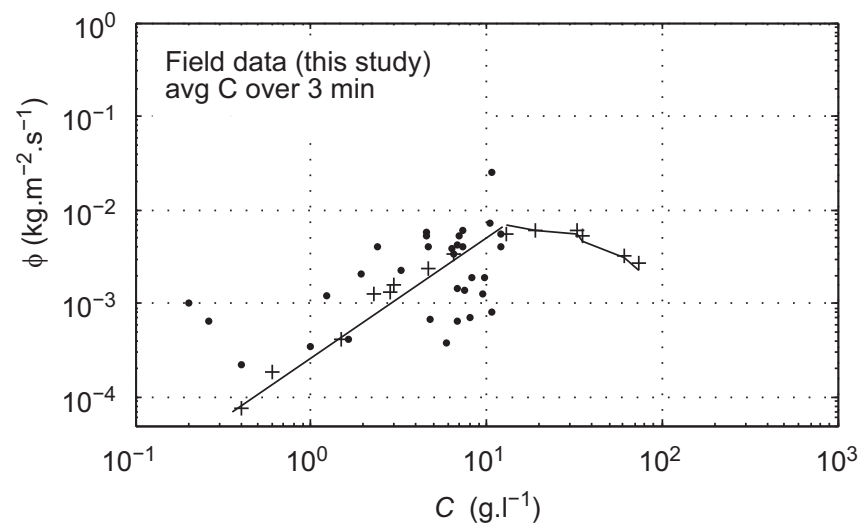

C

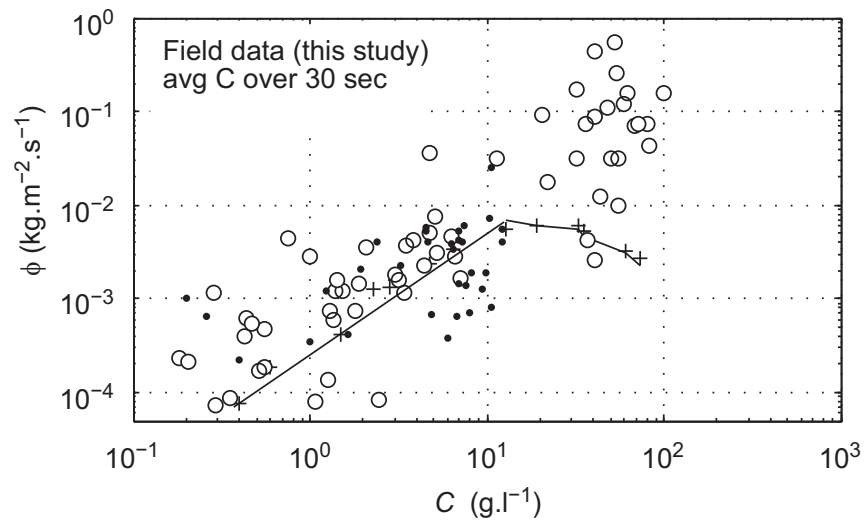

Fig. 9. Mean settling fluxes as a function of suspended sediment concentration. (a) Previous laboratory experiments from Gratiot et al. (2005). Solid line: settling fluxes in quiescent water. Dots: in turbulent conditions. (b) This study. Crosses and solid line: settling fluxes measured in quiescent water onboard. Dots: turbulent fluxes determined from in-situ ADV measurements (Vector 1) averaged over $3 \mathrm{~min}$. (c) Same data as in (b). White circles: turbulent fluxes from in situ ADV measurements averaged over $30 \mathrm{~s}$.

from co-located $32 \mathrm{~Hz}$ records of velocity and SSC averaged over 3 min and already presented in Figs. 7 and 8 . The samples selected are those for which $\overline{w^{\prime} \boldsymbol{C}^{\prime}}$ was positive or upward oriented. Despite a high data scattering, the linear trend is consistent with settling fluxes measured from quiescent water samples, what lets presume that turbulence erosion flux broadly compensate sediment settling fluxes. The coherence between the two datasets is satisfactory, taking into account that ADV data were obtained during one single tidal cycle, during which a variety of near-bed SSC ranges were sampled in natural conditions. This noticeable agreement shows the capability of acoustic velocimetry to evaluate turbulent fluxes in low and medium concentrations. However considering highest values of mean SSC, the comparison of mean turbulent fluxes with tests in quiescent water is only possible for the range of increasing fluxes, below the hindered regime. Mean turbulent fluxes $\overline{W^{\prime} C^{\prime}}$ were measured up to maximum SSC values around $14 \mathrm{~g} \mathrm{l}^{-1}$, which were recorded at mid flood, hour 18 (see Fig. 7). At this time, as stated in Section 3.3, bed resuspension occurred with a possible disruption of the lutocline. Consequently, near-bed concentration decreased, while SSC increased at the level of Vector 1 (see Fig. 8). It is then deduced that at hour 18 Vector 1 starts to measure within a CBS layer. From hour 18 until the end of the record, SSC shows lower variation in time than during the previous resuspension event, ranging between 15 and $7 \mathrm{~g} \mathrm{l}^{-1}$. At the scale of tidal fluctuations in the estuary, this period corresponds to a relatively steady situation. However, significant fluctuations of SSC occur, with a period of several tens of minutes. This suggests that the CBS layer is not stabilized enough to reach and maintain SSC values continuously in the range of fluid mud at the height of Vector 1.

When compared to the laboratory experiments of Gratiot et al. (2005), in situ sediment fluxes were generally smaller. The reason for this offset remains unclear and difficult to elucidate. For the quiescent water tests, the discrepancies observed for concentration in the range $1-10 \mathrm{~g} \mathrm{l}^{-1}$ may result from instrumental biases. Indeed, $\phi$ was deduced from video technique during Gratiot et al. (2005)'s investigations, while in this study settling flux was obtained more directly, by applying the equation of conservation (Eq. (1)). Estimating settling flux from various ways can generate estimates that vary over orders of magnitude, as previously demonstrated by Dyer et al. (1996). However, the relative consistence between ADV near-bed measurements and onboard tests suggests that effects were mainly intrinsic to the fluid-sediment mixture. Indeed in the experience of Gratiot et al. (2005), the organic material was neutralized; thus the density of flocs was much higher than value currently observed for natural mud. Gratiot and Manning (2004) reported values of $1650 \mathrm{~kg} \mathrm{~m}^{-3}$ for flocs in the laboratory, whereas values decreased to $200-250 \mathrm{~kg} \mathrm{~m}^{-3}$ for natural mud in the field. While biology contained in natural mud reinforces flocculation, it leads to flocs of lower density, what may explain the reduction of sediment settling flux for both the rising phase and the hindered regime.

\subsubsection{Turbulent fluxes over short temporal windows}

When considering averaging time period of $3 \mathrm{~min}$, maximum concentration is about $15 \mathrm{gl}^{-1}$. Such data are high enough to describe trends of turbulent fluxes in the increasing flux regime and to compare them with settling fluxes in quiescent water. But mean SSC is too low to bring any information regarding the range of hindered settling. Moreover, it is important to note that the averaging time period governs directly the range of concentration over which turbulent sediment flux can be estimated. For these reasons, and in order to estimate the effect of reducing averaging time, turbulent fluxes were estimated for shorter temporal windows.

The choice of the new averaging time was based on the need for observing high SSC events. In addition, turbulent series should be calculated "with an averaging time greater than the characteristic period of fluctuations, and smaller than the characteristic period for the time evolution of the mean properties" (Trevethan and Chanson, 2010). Following this condition, mean turbulent fluxes $\overline{w^{\prime} C^{\prime}}$ were calculated over time periods of $30 \mathrm{~s}$. While in situ SSC measurements were obtained at a frequency of $32 \mathrm{~Hz}$, each individual turbulent flux value was deduced by averaging 960 instantaneous values. The choice is arbitrary, but in a good agreement with the $10 \mathrm{~s}$ period considered by Trevethan and Chanson (2010) to characterise turbulent flux in a small estuary. 
In their study, they observed 3-4 turbulent bursting events per second so that a $10 \mathrm{~s}$ averaging time period already contains tens of turbulent events. In the present study, we did not calculated turbulent flux for averaging time period lower than $30 \mathrm{~s}$. Fig. 9c shows mean fluxes $\overline{w^{\prime} C^{\prime}}$ and SSC averaged over $30 \mathrm{~s}$, together with previous data already shown in Fig. 9b. With an averaging period of $30 \mathrm{~s}$, the number of samples is greater than for the 3-min averaged data. This is consistent with the fact that when looking at shorter temporal windows, erosive events are more abundant. Reducing averaging time period, mathematically leads also to the observation of larger SSC fluctuations. Several events where SSC $>15 \mathrm{gl}^{-1}$ became visible, and larger sediment fluxes were estimated for a maximum mean SSC up to $99 \mathrm{~g} \mathrm{l}^{-1}$, i.e. the range of the hindered regime for samples in quiescent water.

In the range of SSC between $10^{-1}$ and $14 \mathrm{~g} \mathrm{l}^{-1}$, mean fluxes $\overline{w^{\prime} C^{\prime}}$ averaged over $3 \mathrm{~min}$ and over $30 \mathrm{~s}$ are in good agreement (Fig. 9c). The correlation is better in the range between $10^{-1}$ and $5 \mathrm{~g} \mathrm{l}^{-1}$ because for SSC higher than $5 \mathrm{~g} \mathrm{l}^{-1}$ there is a larger scatter of 3-min fluxes values. Considering the overall trend, shorter temporal windows did not significantly change the order of values obtained, and the dependence of fluxes on SSC remained the same. For SSC $>15 \mathrm{~g} \mathrm{l}^{-1}$, sediment settling fluxes under turbulent conditions increased with increasing SSC. Samples exhibited a fairly linear trend, in relative continuity with the samples of lower SSC range. The turbulent settling fluxes were measured to be in the order of $0.1 \mathrm{~kg} \mathrm{~m}^{-2} \mathrm{~s}^{-1}$ for a SSC value of $50 \mathrm{~g} \mathrm{l}^{-1}$, i.e., 30 times greater than fluxes in quiescent water. Over the whole range of concentration $\left(2-100 \mathrm{~g} \mathrm{l}^{-1}\right)$ the turbulent settling flux increased almost linearly with sediment concentration.

Sediment settling flux was estimated by making the assumption of pseudo-equilibrium conditions between sedimentation flux and turbulent resuspension flux over short spatio-temporal timescales. During this work, it has not been possible to clearly verify the existence of pseudo permanent conditions. While sediment dynamics in estuaries is primarily driven by the tidal forcing, increasing averaging time period to a few minutes would not necessarily reveal pertinent. Such a situation would undoubtedly add a mean velocity fluctuation to the turbulent fluctuations already presents. On the other hand, averaging time periods of a tens of second do probably give more weight to turbulent instabilities. This effect was assumed to be responsible of the wide scattering associated with the turbulent flux timeseries presented in Fig. 9c.

To broadly estimate whether pseudo permanent conditions were obtained or not, the samples selected for calculating turbulent fluxes of Fig. 9c were fitted to the timeseries of mean SSC (3-min averaged) at Vector 1. Result presented on Fig. 10a shows that the samples were distributed randomly along the tidal cycle. This indicates that the selected samples were neither associated with global erosion during acceleration phases nor with global deposition during decelerating phases. It can be observed is the concomitance between periods of high SSC values and of high turbulent fluxes. However, many samples were obtained between hours 16.30 and 20. During this time interval (and especially before 17.30), there is a rapid increase of SSC at Vector 1, therefore this period should be considered as far from any equilibrium. After 17.30 variations of SSC in time are relatively lower despite low frequency fluctuations, and conditions are closer to a pseudo-equilibrium with respect to the tidal cycle. Fig. 10b shows again mean turbulent fluxes over short windows (as in Fig. 9c), with samples labeled following the period of time of the measurement. In addition, samples considered out of equilibrium (between 16.30 and 17.30) were removed. It can be seen that even after removing samples of the highly erosive period (between 16.30 and 17.30), the linear trend remains apparent and fluxes seem to keep increasing in the highest SSC range.

When considering the whole scatter plot of Fig. 10b, samples at high SSC range tend to diverge from the trend given by tests in quiescent water, suggesting a possible effect of turbulence on the hindered regime, similarly to the experimental results of Gratiot

a

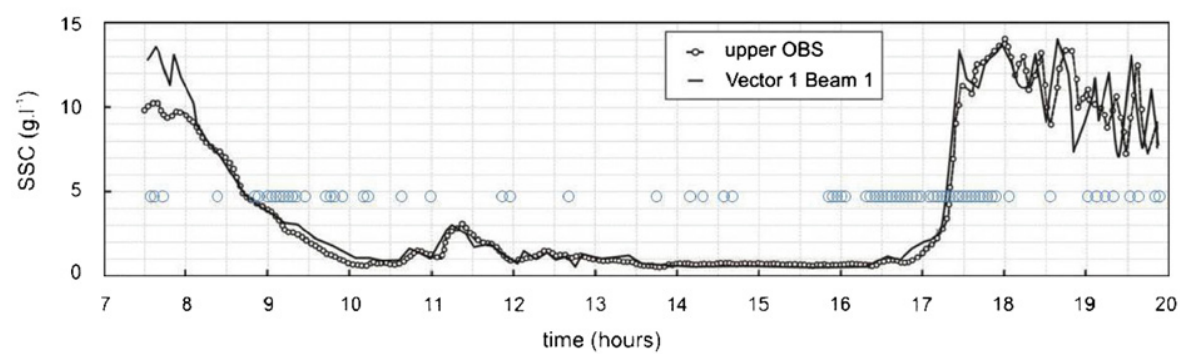

b

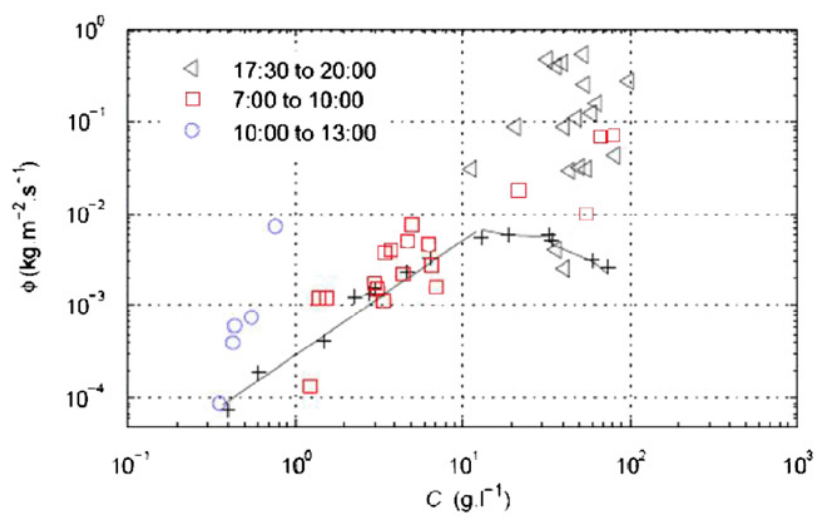

Fig. 10. (a) 3 min-averaged SSC from upper OBS and from inversion of beam 1 of Vector 1 (same data as in Fig. 7c). Open circles indicate the time corresponding to samples taken to calculate turbulent fluxes of Fig. 9c. (b) Turbulent fluxes as a function of SSC, values averaged over $30 \mathrm{~s}$ (same as Fig. 9c). Samples are labeled following the period of time. Measurements between hours 16.00 and 17.30 were removed. 
et al. (2005) illustrated in Fig. 9a. These results would suggest that settling fluxes of cohesive sediment under turbulent conditions may not be affected by the hindered effect acting under quiescent conditions. However, the fully reliability of such a trend in natural conditions needs to be carefully verified.

While laboratory experiments were conducted in fully equilibrium conditions, in situ measurements were obtained in pseudoequilibrium conditions, during short time windows only. In natural field conditions, maximum concentration and CBS layer thickness are difficult to predict; the fact that maximum mean SSC are below $15 \mathrm{~g} \mathrm{l}^{-1}$ when averaged over 3 min suggests that experiments were conducted out of the range of persistent steady concentrated fluid mud, at least at the position of Vector 1 . Then high SSC in CBS layers was reached only during short events. A wider range of concentration and mean fluxes in persistent layers with high SSC averaged over several minutes are necessary to verify these trends. Only the further repetition of such instrumental deployments in more favorable natural configurations would provide such required SSC conditions.

Finally the data scattering in Figs. 9b, $\mathrm{c}$ and $10 \mathrm{~b}$ remain relatively important, suggesting that turbulent sediment fluxes measurements in the field based on acoustic scattering theory still needs improvement. This work was a first trial in the application of well known high-resolution acoustic backscattering technologies and associated methods validated for non-cohesive fine sand suspensions, to realistic mud suspension conditions encountered in the field.

\section{Summary and conclusions}

An experiment was conducted over one tidal cycle in the highly turbid waters of the Gironde estuary, involving for the first time acoustic measurements of near-bottom turbulence and suspended sediment concentration in this estuarine system. Comparisons among a complete set of instruments reveal that commercial acoustic Doppler velocimeters are suitable for measuring turbulence velocities in mud mixtures with averaged concentration up to $15 \mathrm{~g} \mathrm{l}^{-1}$. Provided that a set of calibrations is available, it is possible to invert acoustic backscattering to assess concentration and therefore turbulent fluxes, $\overline{w^{\prime} c^{\prime}}$. In this case, we used OBS turbidimeters independently calibrated in a SSC range between 0.5 and $300 \mathrm{~g} \mathrm{l}^{-1}$.

High-frequency near-bed velocities, turbulent shear and SSC were analyzed. They highlight complex processes related to fluid mud entrainment and/or advection in a turbulent, sheared flow, with strong asymmetry between ebb and flood stages. Exhaustive analysis has to be conducted to better understand the main patterns observed here for the first time in this portion of the Gironde estuary. It is likely that high shear values during ebb are due to some wake effect from local artificial structures close to the study zone. Further investigations in a portion of the channel where the flow is not perturbated by such obstacles will provide relevant data to remove any ambiguity on near-bed shear asymmetry.

Mean settling fluxes $\overline{W^{\prime} C^{\prime}}$ were calculated from co-located velocity and SSC measured by the ADV. Fluxes averaged over 3 min showed a linear increase for increasing SSC, in good agreement with tests in quiescent water for an SSC range below $15 \mathrm{gl}^{-1}$, but absolute values were smaller than those obtained in laboratory from Gratiot et al. (2005). This noticeable agreement between turbulent fluxes and sedimentation fluxes shows the capability of acoustic velocimetry to evaluate turbulent fluxes in low and medium concentrations. Averaging turbulent fluxes and SSC over shorter periods of $30 \mathrm{~s}$ allowed to increase the mean SSC in the CBS layer up to $99 \mathrm{~g} \mathrm{l}^{-1}$. At this range of SSC, mean turbulent fluxes were still increasing, suggesting a possible effect of turbulence on the reduction (or delay) of the initiation of the hindered settling, as shown previously in laboratory experiments. However, SSC averaged over $3 \mathrm{~min}$ were too low to cover the range of stabilized fluid mud and therefore to fully conclude on the effect of delayed or inhibited hindering. These results should be confirmed by a more comprehensive analysis and interpretation of similar data obtained under different tidal conditions and under higher concentration ranges in the estuarine environment.

\section{Acknowledgment}

The authors thank the crew of the RV "Côte de la Manche" (INSU-CNRS) for their assistance, Dr. Jean-Claude Brun-Cottan (University of Caen) and Pr. Stéphane Abadie (University of Pau, Anglet) for making their ADV Velocimeters available. The two anonymous reviewers and Dr. Pierre Le Hir are also acknowledged for their useful comments and suggestions.

\section{References}

Allen, G.P., Sauzay, P., Castaing, P., Jouanneau, J-M. 1977. Transport and deposition of suspended sediment in the Gironde estuary. In: Wiley, M. (Ed.) Estuarine Processes. Academic Press, New York, pp. 63-81.

Allen, G.P., Salomon, J.C., Bassoullet, P., Du Penhoat, Y., De Grandpré, C., 1980 Effects of tides on mixing and suspended sediment transport in macrotidal estuaries. Sedimentary Geology 26, 69-90.

Cea, L., Puertas, J., Pena, L., 2007. Velocity measurements on highly turbulent free surface flow using ADV. Experiments in Fluids 42, 333-348.

Fugate, D.C., Friedrichs, C.T., 2002. Determining concentration and fall velocity of estuarine particle populations using ADV, OBS and LISST. Continental Shelf Research 22 (11-13), 1867-1886.

Dyer, K.R., Cornelisse, J., Dearnaley, M.P., Fennessy, M.J., Jones, S.E., Kappenberg, J., McCave, I.N., Pejrup, M., Puls, W., Van Leussen, W., Wolfstein, K., 1996. A comparison of in situ techniques for estuarine floc settling velocity measurement. Journal of Sea Research 36 (1-2), 15-29.

Gratiot, N., 2004. Flocculation of Mud Suspensions in the Gironde Estuary: Experimental Measurements of Settling Flux in a Column. Technical Report, in French, 4 pp.

Gratiot, N., Mory, M., Auchere, D., 2000. An acoustic Doppler velocimeter (ADV) for the characterization of turbulence in concentrated fluid mud. Continental Shelf Research 20, 1551-1567.

Gratiot, N., Michallet, H., Mory, M., 2005. On the determination of the settling flux of cohesive sediments in a turbulent fluid. Journal of Geophysical Research 110, C06004.

Gratiot, N., Manning, A.J., 2004. An experimental investigation of floc's characteristics in a diffusive turbulent flow. Journal of Coastal Research SI(41), 105-113.

Ha, H.K., Hsu, W.-Y., Maa, J.P.-Y., Shao, Y.Y., Holland, C.W., 2009. Using ADV backscatter strength for measuring suspended cohesive sediment concentration. Continental Shelf Research 29, 1310-1316.

Kineke, G.C., Sternberg, R.W., 1992. Measurements of high concentration suspended sediments using the optical backscatterance sensor. Marine Geology $108,253-258$

Lane, S.N., Biron, P.M., Bradbrook, K.F., Butler, J.B., Chandler, J.H., Crowel, M.D. McLelland, S.J., Richards, K.S., Roy, A.G., 1998. Three-Dimensional measurement of river channel flow processes using acoustic Doppler velocimetry. Earth Surface Processes and Landforms 23, 1247-1267.

Le Hir, P., Bassoullet, P., Jestin, H., 2001. Application of the continuous modelling concept to simulate high-concentration suspended sediment in a macrotida estuary. In: McAnally, W.H., Mehta, A.J. (Eds.), Coastal and Estuarine Fine Sediments Processes. Elsevier, Amsterdam, pp. 229-247.

Manning, A.J., Bass, S., 2006. Variability in cohesive sediment settling fluxes: observations under different estuarine tidal conditions. Marine Geology 235 (1-4), 177-192.

Martin, V., Fisher, T.S.R., Millar, R.G., Quick, M.C., 2002. ADV data analysis for turbulent flows: low correlation problem. In: Proceedings of the Conference on Hydraulic Measurements and Experimental Methods, July 28-August 1, 2002, ASCE/EWRI, Estes Park, Col. (USA), 10 pp.

Merckelbach, L.M. 2006. A model for high-frequency acoustic Doppler current profiler backscatter from suspended sediment in strong currents. Continental Shelf Research 26, 1316-133511, 1316-1335.

Moore, S.A., Hay, A.E., 2009. Angular scattering of sound from solid particles in turbulent suspension. Journal of Acoustical Society of America 126 (3), 1046-1056.

Simpson, J.H., Williams, E., Brasseur, L.H., Brubaker, J.M., 2005. The impact of tidal straining on the cycle of turbulence in a partially stratified estuary. Continental Shelf Research 25, 51-64.

Sottolichio, A., Le Hir, P., Castaing, P., 2001. Modeling mechanisms for the stability of the turbidity maximum in the Gironde estuary. In: McAnally, W.H. 
Mehta, J.C. (Eds.), Coastal and Estuarine Fine Sediments Processes. Elsevier, Amsterdam, pp. 373-386.

Sottolichio, A., Castaing, P., 1999. A synthesis on seasonal dynamics of highly concentrated structures in the Gironde estuary. Comptes Rendus Académie des Sciences, Paris, Earth and Planetary Sciences 1999 (329), 795-800.

Tessier, C., Le Hir, P., Lurton, X., Castaing, P., 2008. Estimation de la matière en suspension à partir de l'intensité acoustique rétrodiffusée des courantomètres acoustiques à effet Doppler (ADCP). Comptes Rendus Geoscience 340, 57-67.

Thorne, P.D., Hardcastle, P.J., Soulsby, R.L., 1993. Analysis of acoustic measurements of suspended sediments. Journal of Geophysical Research 98 (C1), 899-910.

Thorne, P.D., Hardcastle, P.J., 1997. Acoustic measurements of suspended sediment in turbulent currents and comparison with in-situ samples. Journal of Acoustical Society of America 101 (5), 2603-2614.

Thorne, P.D., Hanes, D.M., 2002. A review of acoustic measurement of small-scale sediment processes. Continental Shelf Research 22 (2002), 603-632.

Thorne, P.D., Buckingham, M.J., 2004. Measurements of scattering by suspensions of irregularly shaped sand particles and comparison with a single parameter modified sphere model. Journal of Acoustical Society of America 116 (5), 2876-2889.

Thorne, P.D., Meral, R., 2008. Formulations for the scattering properties of sandy sediments for use in the application of acoustics to sediment transport. Continental Shelf Research 28, 309-317.
Thorne, P.D., Hurther, D., 2009. Acoustical Observations of Velocity and Suspended Sediment Structures due to Oscillatory Flow Over a Rippled Bed. In: Proceedings of the Coastal Dynamics 09, September 7-11 2009, Tokyo, Japan.

Toorman, E., 1992. Modelling of Fluid Mud Flow and Consolidation, Ph.D. thesis, Hydraul. Lab., Katholieke Univ. Leuven, Leuven, Belgium.

Trevethan, M., Chanson, H., 2010. Turbulence and turbulent flux events in a small estuary. Environmental Fluid Mechanics 10, 345-368. doi:10.1007/s10652009-9134-7.

Verney, R., Deloffre, J., Brun-Cottan, J.-C., Lafite, R., 2007. The effect of waveinduced turbulence on intertidal mudflats: impact of boat traffic and wind. Continental Shelf Research 27 (2007), 594-612.

Voulgaris, G., Trowbridge, G., 1998. Evaluation of the acoustic Doppler velocimeter (ADV) for turbulence measurements. Journal of Atmosperic and Oceanic Technology 15, 272-289.

Winterwerp, J.C., Uittenbogaard, R.E., de Kok, J.M., 2001. Rapid siltation from saturated mud suspensions. In: McAnally, W.H., Mehta, A.J. (Eds.), Coastal and Estuarine Fine Sediments Processes. Elsevier, Amsterdam, pp. 125-146.

Winterwerp, J.C., 2002. On the flocculation and settling velocity of estuarine mud. Continental Shelf Research 22, 1339-1360.

You, Z.-J., 2004. The effect of suspended sediment concentration on the settling velocity of cohesive sediment in quiescent water. Ocean Engineering 31, 1955-1965. 